\title{
MONITORAMENTO DA SUSCETIBILIDADE DE POPULAÇÕES DE Brevipalpus phoenicis (GEIJSKES, 1939) \\ (ACARI: TENUIPALPIDAE) A ACARICIDAS ORGANOESTÂNICOS EM CITROS
}

\section{ROBERTO HIROYUKI KONNO}

Engenheiro Agrônomo

Orientador: Prof. Dr. Celso Omoto

\begin{abstract}
Dissertação apresentada à Escola Superior de Agricultura "Luiz de Queiroz", Universidade de São Paulo, para obtenção do título de Mestre em Ciências, Área de Concentração: Entomologia.
\end{abstract}

PIRACICABA

Estado de São Paulo - Brasil

Agosto - 2000 
Dados Internacionais de Catalogação na Publicação (CIP)

DIVISÃO DE BIBLIOTECA E DOCUMENTAÇÃO - Campus "Luiz de Queiroz"/USP

\section{Konno, Roberto Hiroyuki}

Monitoramento da suscetibilidade de populações de Brevipalpus phoenicis

(Ciijskes, 1939) (Acari: Tenuipalpidae) a acaricidas organoestânicos em citros /

Roberto Hiroyuki Konno. - - Piracicaba, 2000.

$62 \mathrm{p}$.

Dissertação (mestrado) - - Escola Superior de Agricultura Luiz de Queiroz, 2000.

Bibliografia.

1. Ácaro 2. Entomologia agrícola 3. Leprose citrica 4. Monitoramento 5. Resistência ao pesticida I. Título

$\operatorname{CDD} 634.3$

Termitida a copia total ou parcial deste documento, desde que citada a fonte - O auton 
Aos meus pais

Maria e Takayuki

Ofereço

À minha irmã Angela

e meus tios Setuko e Antonio

Dedico 


\section{AGRADECIMENTOS}

Ao Prof. Dr. Celso Omoto pelo apoio, incentivo e orientação na realização deste trabalho.

Aos professores do Curso de Pós-Graduação em Entomologia da ESALQ/USP, pelos ensinamentos transmitidos durante o Curso.

À Fundação de Amparo à Pesquisa do Estado de São Paulo - FAPESP pelo financiamento do projeto e concessão da bolsa de estudos.

Ao Fundo Paulista de Defesa da Citricultura - Fundecitrus e à Fischer Agropecuária S.A. pelo apoio ao projeto.

À Hokko do Brasil e à Cyanamid Química do Brasil Ltda. pelo fornecimento de acaricidas.

Aos engenheiros agrônomos e colegas de curso Everaldo Batista Alves e Fernando Joly Campos pela amizade, companheirismo e colaboração.

Ao bolsista Claudio Roberto Franco pelos auxilios prestados na realização do trabalho.

Aos colegas do Curso de Pós-Graduação em Entomologia pela amizade e companheirismo.

Aos amigos Cristiano Alberto de Andrade, Luís Pedro de Mello Plese, Luciano Mendes Souza Mendes Vaz, Catia Akemi Morii e Cristiana Yamamoto. 


\section{SUMÁRIO}

Página

RESUMO

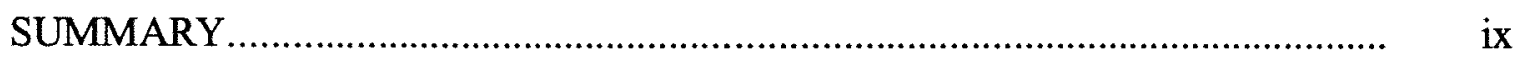

1 INTRODUÇÃO

2 REVISÃO DE LITERATURA.................................................................. 4

2.1 Aspectos bioecológicos de Brevipalpus phoenicis............................................... 4

2.2. Resistência de ácaros a acaricidas...................................................................

2.2.1 Fatores que afetam a evolução da resistência de ácaros a acaricidas................ 7

2.2.2 Deteç̧ão e monitoramento da resistência........................................................ 12

2.2.3 Resistência de ácaros a acaricidas organoestânicos......................................... 15

2.3 Manejo da resistência de ácaros a acaricidas...................................................... 18

3 MATERIAL E MÉTODOS..................................................................... 22

3.1 Criação de Brevipalpus phoenicis em laboratório................................................ 22

3.2 Metodologia de bioensaio............................................................................ 23

3.3 Caracterização toxicológica de populações de Brevipalpus phoenicis a óxido de fenbutatin e cihexatin

3.4 Efeito da umidade na persistência de resíduos de óxido de fenbutatin............... 25

3.5 Monitoramento da suscetibilidade de populações de Brevipalpus phoenicis a óxido de fenbutatin e cihexatin. 
4 RESULTADOS E DISCUSSÃO.

4.1 Caracterização toxicológica de populações de Brevipalpus phoenicis a óxido de fenbutatin e cihexatin...

4.2 Efeito da umidade na persistência de resíduos de óxido de fenbutatin.

4.3 Monitoramento da suscetibilidade de populações de Brevipalpus phoenicis aos acaricidas óxido de fenbutatin e cihexatin.

5 CONCLUSÕES 


\section{MONITORAMENTO DA SUSCETIBILIDADE DE POPULAÇÕES DE Brevipalpus phoenicis (GEIJSKES, 1939) (ACARI: TENUIPALPIDAE) A ACARICIDAS ORGANOESTÂNICOS EM CITROS}

Autor: Roberto Hiroyuki Konno Orientador: Prof. Dr. Celso Omoto

\section{RESUMO}

O principal objetivo do presente trabalho foi o de coletar informações básicas para a implementação de um programa de manejo da resistência de Brevipalpus phoenicis (Geijskes, 1939) a acaricidas organoestânicos em pomares de citros do Estado de São Paulo. Inicialmente, as linhas básicas de suscetibilidade aos acaricidas óxido de fenbutatin e cihexatin foram obtidas para uma população suscetivel de referência de $B$. phoenicis através de um bioensaio de contato residual. Baseado na curva de concentração-resposta dessa população para os dois acaricidas, a concentração diagnóstica de $180 \mathrm{mg}$ de [IA] / L de água destilada foi definida para ser utilizada em programas de monitoramento da suscetibilidade de populações de $B$. phoenicis a esses acaricidas. Posteriormente, foram realizados estudos de persistência de resíduos de óxido de fenbutatin em discos de folha de citros mantidos em diferentes condições de umidade relativa $(30,50,70$ e $90 \%$ de UR). Os resultados demonstraram que o fator umidade não 
apresentou efeito significativo na atividade desse acaricida para uma possível discriminação da resistência de $B$. phoenicis a óxido de fenbutatin. E por último, foi realizado um levantamento da suscetibilidade aos acaricidas óxido de fenbutatin e cihexatin em populações de $B$. phoenicis coletadas em pomares comerciais com diferentes regimes de uso de acaricidas organoestânicos nos últimos 5 anos. Todas as populações testadas apresentaram suscetibilidade a óxido de fenbutatin e cihexatin semelhante ao da população suscetível de referência, com exceção de uma população que apresentou uma porcentagem de sobrevivência a cihexatin $(10,7 \%)$ significativamente maior do que a da população suscetivel na concentração diagnóstica. Portanto, apesar do intenso uso de acaricidas organoestânicos para controle de $B$. phoenicis em citros no Estado de São Paulo, as populações desse ácaro ainda apresentam uma alta suscetibilidade a acaricidas óxido de fenbutatin e cihexatin. 


\title{
MONITORING THE SUSCEPTIBILITY OF Brevipalpus phoenicis (GEIJSKES， 1939) (ACARI: TENUIPALPIDAE) TO ORGANOTIN ACARICIDES IN CITRUS
}

\author{
Author: Roberto Hiroyuki Konno \\ Adviser: Prof. Dr. Celso Omoto
}

\section{SUMMARY}

The major objective of this research was to collect the basic information for implementing a resistance management program of Brevipalpus phoenicis (Geijskes, 1939) to organotin acaricides in citrus groves from the State of São Paulo, Brazil. Initially, baseline susceptibility data of the susceptible reference population of $B$. phoenicis to fenbutatin oxide and cyhexatin were obtained with the use of a residual contact bioassay. Based on concentration-response data of this population to these acaricides, a diagnostic concetration of $180 \mathrm{mg}$ of [AI] / $\mathrm{L}$ of distilled water was defined for both fenbutatin oxide and cyhexatin in order to be used in a program for monitoring the susceptibility of $B$. phoenicis to these acaricides. Studies on persistence of fenbutatin oxide residues on citrus leaf disks kept under different relative humidity conditions (30, 50, 70 and $90 \% \mathrm{RH})$ showed that the humidity did not affect the activity of this acaricide for a possible discrimination of $B$. phoenicis resistance to fenbutatin oxide. Then, a survey of 
the susceptibility to fenbutatin oxide and cyhexatin was conducted in populations of $B$. phoenicis collected from citrus groves with different regimes of organotin acaricide use in the past 5 years. All populations tested showed susceptibilities to fenbutatin oxide and cyhexatin similar to the susceptible population; except for one population which showed a significant higher survivorship to cyhexatin than that for the susceptible population at the diagnostic concentration. Therefore, although the intense use of organotin acaricides in citrus groves in the State of São Paulo, the susceptibilities of $B$. phoenicis populations to fenbutatin oxide and cyhexatin are still very high. 


\section{INTRODUÇÃO}

O ácaro da leprose Brevipalpus phoenicis (Geijskes, 1939) é uma das principais pragas da cultura do citros no Brasil devido aos sérios prejuizos que acarreta na produção, principalmente, em virtude da transmissão do agente causal da leprose dos citros (Oliveira, 1986; Chiavegato, 1987; Kitajima et al., 1995). Os sintomas da leprose são manifestados através de lesões em folhas, ramos e frutos e em casos severos, pode ocorrer a queda das folhas e a morte dos ramos. As lesões depreciam os frutos e podem causar queda prematura dos frutos (Rossetti, 1995; Kitajima et al., 1995)

O controle de $B$. phoenicis tem sido realizado através da utilização de produtos químicos. Estima-se que mais de 90 milhões de dólares são gastos com acaricidas na citricultura brasileira, o que significa, aproximadamente, $20 \%$ do custo de produção (Salvo Filho, 1997). Segundo o levantamento apresentado por Nakano (1995), 44\% dos ingredientes ativos comercializados no ano de 1994 , para o controle de B. phoenicis, pertenciam ao grupo dos organoestânicos (por ex.: óxido de fenbutatin, cihexatin e azociclotin). Dados obtidos através do Painel das Empresas de 1998 revelaram que aproximadamente $40 \%$ das áreas tratadas com acaricidas em citros foram com organoestânicos. Atualmente este grupo de acaricida tem sido o mais utilizado devido a sua eficácia no controle de B. phoenicis, associada a uma certa seletividade a inimigos naturais (Yamamoto, 1995).

Apesar do grande esforço direcionado ao controle de B. phoenicis, problemas relacionados à eficiência de controle com alguns acaricidas têm sido 
esporadicamente reportados por agricultores e técnicos ligados à área citrícola (Omoto, 1995a, 1998). As falhas no controle são manifestadas pelo encurtamento do período residual dos acaricidas em alguns pomares, isto é, populações de ácaro da leprose têm aumentado rapidamente após uma pulverização. Obviamente, o momento da aplicação (nível de ação) e a qualidade da aplicação (dosagem do acaricida, calibragem dos equipamentos de pulverização e a condição climática) são decisivos para um controle satisfatório desse ácaro. Sem dúvida, estes fatores são responsáveis pelo baixo desempenho de acaricidas em diversas localidades. No entanto, devido à aplicação intensa de acaricidas nos pomares de citros, podese levantar a hipótese de que a evolução da resistência de $B$. phoenicis a acaricidas é um dos fatores que vem contribuindo para a redução da eficácia de alguns acaricidas (Gravena, 1994; Omoto, 1995a,b). Recentemente, Alves (1999) detectou e caracterizou a resistência de $B$. phoenicis ao acaricida dicofol. Dessa forma é possível inferir que falhas de controle do ácaro da leprose com uso de acaricidas organoestânicos possam, também, estar relacionadas com a resistência.

Um dos grandes entraves em programas de manejo de pragas (MIP), envolvendo o uso de produtos químicos, é a evolução da resistência (Georghiou, 1983; Croft, 1990; Denholm \& Rolland, 1992). Como conseqüências drásticas do desenvolvimento da resistência estão a aplicação mais freqüente de pesticidas, o uso de doses elevadas, de misturas de pesticidas e/ou a substituição por um outro produto de maior toxicidade, comprometendo os programas de MIP devido ao aumento no custo de controle, maior destruição de inimigos naturais e maior contaminação do meio ambiente com os pesticidas (Georghiou, 1983). Associado a esses fatores, sabe-se que a descoberta de uma nova molécula química está se tornando cada vez mais cara e difícil. Estudos da resistência de pragas a pesticidas são de grande importância para a preservação da eficiência dos produtos químicos que se enquadram dentro da filosofia do manejo integrado de pragas como é o caso dos acaricidas organoestânicos. 
O objetivo principal do presente trabalho foi o de coletar informações básicas para implementação de um programa preventivo de manejo da resistência do ácaro da leprose aos acaricidas óxido de fenbutatin e cihexatin. Os objetivos específicos foram:

-Caracterizar a linha-básica de suscetibilidade de B. phoenicis aos acaricidas óxido de fenbutatin e cihexatin;

-Avaliar o efeito da degradação de resíduos de óxido de fenbutatin mantidos em diferentes umidades relativas no controle de B. phoenicis;

-Avaliar o efeito de diferentes regimes de uso de acaricidas organoestânicos sobre a suscetibilidade de populações de $B$. phoenicis a aos acaricidas óxido de fenbutatin e cihexatin. 


\section{REVISÃO DE LITERATURA}

\subsection{Aspectos bioecológicos de Brevipalpus phoenicis}

O ácaro da leprose Brevipalpus phoenicis (Geijskes, 1939) possui uma ampla distribuição geográfica e um grande número de hospedeiros. Em revisão feita por Haramoto (1969) foi constatado um maior número de relatos de ocorrência do ácaro da leprose em áreas próximas aos trópicos, onde as condições climáticas e a abundância de hospedeiros como citros, cafeeiro, chá e outros, favorecem a sua ocorrência. Segundo Chiavegato \& Mischan (1987), mais de 80 gêneros de plantas têm sido relacionados como hospedeiros deste ácaro, sendo o citros o principal hospedeiro. Trindade \& Chiavegato (1994) encontraram 34 espécies de plantas hospedeiras de B. phoenicis incluindo plantas cultivadas, ornamentais e daninhas, muitas das quais são comumente encontradas nos pomares de citros do Estado de São Paulo.

A biologia de $B$. phoenicis foi estudada por diversos pesquisadores (Haramoto, 1969; Lal, 1978; Chiavegato, 1986; Trindade, 1990; Trindade \& Chiavegato, 1994; Alves, 1999). O ciclo de vida do ácaro da leprose é constituído pelas fases de ovo, larva, protoninfa e deutoninfa, sendo que cada ínstar é dividido em períodos de alimentação e quiescência (Flechtmann, 1977). O ácaro da leprose se reproduz, principalmente, por partenogênese telitoca, onde fêmeas não fecundadas dão origem a fêmeas (Helle et al., 1980). A reprodução sexuada também é verificada, porém os machos são relativamente raros na população. 
Diferentes fatores ambientais podem afetar o desenvolvimento do ácaro da leprose. Haramoto (1969) estudou o efeito da temperatura sobre o desenvolvimento de $B$. phoenicis, utilizando frutos de mamão como substrato. Nesse estudo, observou-se que o ciclo do ácaro era reduzido em temperaturas mais elevadas. Porém, a sobrevivência de ovo-adulto foi menor em temperatura $\mathrm{s}$ superiores a $30^{\circ} \mathrm{C}$, assim como em temperaturas inferiores a $20^{\circ} \mathrm{C}$. À temperatura de $25^{\circ} \mathrm{C}$ e umidade relativa do ar de $65 \%$ a $70 \%$, o ciclo foi completado em 25 dias.

Lal (1978) estudou o efeito de diferentes substratos e temperaturas sobre o ciclo biológico do ácaro da leprose. Os substratos utilizados foram folhas de Oroxylum indicum Vent e Clerodendron siphonanthus $\mathrm{R}$.Br. e as temperaturas avaliadas foram de $21,2^{\circ} \mathrm{C}$ e $26,6^{\circ} \mathrm{C}$. À temperatura de $26,6^{\circ} \mathrm{C}$, o ciclo de ovoadulto foi de 20,7 dias e 20,2 dias para $O$. indicum e $C$. siphonanthus, respectivamente. À temperatura de $21,2^{\circ} \mathrm{C}$, o ciclo de ovo-adulto foi de 29,0 dias e 28,3 dias, respectivamente. O efeito da temperatura foi mais pronunciado do que o efeito do substrato.

As variedades cítricas também podem afetar o desenvolvimento do ácaro da leprose, sendo que Valência e Tangor Murcote foram os melhores substratos quando comparados com limão Taiti, limão Siciliano e lima da Pérsia (Chiavegato \& Mischan, 1987). Os ácaros, quando criados sobre Valência e Tangor Murcote, deixaram um maior número de descendentes e um menor número de ácaros mortos ou presos na barreira de cola.

Chiavegato (1986) estudou a biologia do ácaro sobre frutos e folhas de laranjeira Valência nas temperaturas de $20^{\circ} \mathrm{C}$ e $30^{\circ} \mathrm{C} \pm 1^{\circ} \mathrm{C}$, umidade relativa de $60 \pm 10 \%$ e fotofase de $14 \mathrm{~h}$. À temperatura de $30^{\circ} \mathrm{C}$, o período de ovo-adulto foi de 14,4 dias em frutos, contra 17,6 dias obtido em folhas. Nessa mesma temperatura, o período de pré-oviposição foi mais rápido nos frutos (1,9 dias) 
quando comparado às folhas (3,6 dias). Dessa forma, o autor concluiu que frutos de laranja são os melhores substratos para criação do ácaro da leprose do que as folhas.

Frutos de laranja com sintomas de verrugose, doença causada pelo fungo Elsinoe fawcetti Bitancourt \& Jenkins, por apresentarem superfície mais rugosa foram mais favoráveis ao desenvolvimento do ácaro da leprose (Nakano et al., 1987; Albuquerque et al., 1995; Barreto \& Pavan, 1995). Quando o ácaro era criado em frutos com sintomas de verrugose, a população após certo tempo, apresentou maior número de sobreviventes, maior oviposição e menor número de ácaros mortos ou presos na barreira de cola, quando comparados com ácaros criados em frutos sem sintomas de verrugose (Albuquerque et al., 1995). Dessa forma, o controle da verrugose é citado como um método para otimizar a eficiência dos acaricidas no controle do ácaro (Nakano et al., 1987).

Oliveira (1986) estudou a flutuação populacional de $B$. phoenicis nos pomares de citros do Estado de São Paulo. O ácaro foi encontrado durante todo o ano, porém a sua densidade apresentou um aumento expressivo a partir dos meses de março-abril, que corresponde ao período de diminuição das precipitações pluviométricas. $O$ pico populacional coincidiu com a primavera (setembrooutubro), diminuindo com o início das chuvas (novembro-dezembro). Segundo Oliveira (1995), outros fatores podem estar associados à flutuação populacional do ácaro como fenologia do hospedeiro e presença de predadores, que podem interferir diretamente sobre a população ou indiretamente, favorecendo o desenvolvimento de possíveis agentes que atuam sobre a população de $B$. phoenicis 


\subsection{Resistência de ácaros a acaricidas}

A resistência tem sido definida como uma habilidade desenvolvida por uma população de um organismo em tolerar doses de um tóxico que seriam letais para a maioria dos indivíduos da população normal da espécie (World Health Organization, citado por Croft \& Van de Bann, 1988). Georghiou \& Tejeda (1991) relataram que até o final da década de 80, haviam mais de 504 espécies de insetos e ácaros resistentes a pelo menos uma classe de compostos químicos. Desse total, $56,1 \%$ eram pragas agrícolas, $39,3 \%$ eram insetos de importância médico veterinária e $4,6 \%$ eram ácaros predadores ou insetos benéficos. Com relação aos grupos de pragas de importância agricola, foi constatado que os ácaros corresponderam a $14,1 \%$ das espécies resistentes.

O primeiro caso de ácaro resistente a um acaricida foi relatado em 1937, com a detecção de linhagens de Tetranychus urticae (Koch) (Acari: Tetranychidae) resistentes a um composto à base de selênio; porém, os grandes problemas com resistência iniciaram-se com o uso intensivo de acaricidas organosintéticos (Cranham \& Helle, 1985). A partir de levantamentos bibliográficos realizados por Croft \& Van de Baan (1988) e Messing \& Croft (1996) foi constatado que algumas espécies de ácaros da família Tetranychidae e Eriophyidae se apresentavam resistentes a quase todos os grupos químicos.

\subsubsection{Fatores que afetam a evolução da resistência de ácaros a acaricidas}

O processo determinante no desenvolvimento da resistência é a grande pressão de seleção exercida por constantes aplicações de um determinado produto químico. No início da evolução da resistência, estima-se que a freqüência de alelos resistentes em uma população seja baixa, na ordem de $10^{-2}$ a $10^{-13}$ (Roush \& McKenzie, 1987). Georghiou \& Taylor (1977a, b) dividiram os fatores que 
afetam o desenvolvimento da resistência em genéticos, bioecológicos e operacionais.

Os fatores genéticos estão relacionados com o número de genes envolvidos na resistência, dominância dos alelos resistentes e valor adaptativo dos indivíduos resistentes (Roush \& MacKenzie, 1987). Os ácaros tetraniquídeos de uma forma geral apresentam um número reduzido de cromossomos (Helle \& Pijnacker, 1985), o que pode favorecer a evolução da resistência. Segundo Helle et al. (1980), B. phoenicis apresenta um reduzido número de cromossomos $(n=2)$. Em função dessa característica, o ácaro da leprose apresenta grandes chances de que dois ou mais mecanismos distintos de resistência se localizem num mesmo cromossomo. Assim, a utilização de um determinado acaricida pode levar à seleção de ácaros resistentes a um outro grupo de acaricidas, se os genes que conferem resistência a estes dois grupos de acaricidas estiverem no mesmo cromossomo. Essas características intrínsecas do ácaro da leprose fazem com que o desenvolvimento da resistência seja, teoricamente, bastante rápida com a utilização contínua de acaricidas (Omoto, 1995b).

As diferenças no valor adaptativo entre os indivíduos suscetíveis e resistentes de uma população podem afetar a evolução da resistência (Roush \& McKenzie, 1987). Em revisão realizada por Cranhan \& Helle (1985) foi verificado que, entre os ácaros tetraniquídeos, as populações resistentes podem apresentar redução na fertilidade e maior tempo para completar o seu desenvolvimento. Omoto et al. (1995) estudando a dinâmica da resistência de Phyllocoptruta oleivora (Ashmead) (Acari: Eriophyidae) ao dicofol, observaram que a freqüência de indivíduos resistentes diminuía quando a aplicação de dicofol era interrompida, mostrando que de certa forma havia alguma desvantagem associada à resistência ao dicofol.

Estudo sobre a biologia de linhagens suscetível e resistente de $B$. phoenicis ao dicofol, realizado por Alves (1999) mostrou que a população 
resistente apresentava menor valor adaptativo e que o custo estava relacionado à menor fecundidade e longevidade da população resistente em relação à suscetível.

Flexner et al. (1989) estudando a dinâmica da resistência de $T$. urticae a acaricidas organoestânicos, observaram que a população suscetivel apresentava um menor tempo de desenvolvimento e uma maior porcentagem de sobrevivência de ovo a adulto, quando comparados aos ácaros provenientes de populações resistentes. Um outro fator observado nesse estudo foi a maior proporção de fêmeas na população suscetível de campo. Essas diferenças entre as populações indicaram que o custo adaptativo poderia estar influenciando na reversão à suscetibilidade em condições de laboratório. Por outro lado, Pree (1987) observou que populações de Panonychus ulmi Koch (Acari: Tetranychidae) resistentes ao cihexatin e dicofol não mostraram desvantagens adaptativas relacionadas aos parâmetros biológicos avaliados (tempo de desenvolvimento e fecundidade), quando comparados com a população suscetível. A única diferença observada pelo autor foi que a população resistente ao cihexatin apresentou uma maior proporção de fêmeas.

Dentre os fatores bioecológicos que afetam o desenvolvimento da resistência destacam-se o modo de reprodução, hábito alimentar, mobilidade da espécie, presença de refúgio para indivíduos suscetíveis e número de gerações por ano (Georghiou \& Taylor, 1977a). Segundo Helle et al. (1980), B. phoenicis é haplóide e se reproduz, predominantemente, por partenogênese telítoca do tipo automítica, assim todos os seus descendentes, provenientes de ovos não fertilizados, serão geneticamente idênticos à progenitora. Dessa forma, a evolução da resistência pode ocorrer de maneira rápida para $B$. phoenicis com o uso contínuo de um mesmo acaricida (Omoto, 1998).

Associado ao modo de reprodução, outro fator que influencia o desenvolvimento da resistência é o alto potencial biótico apresentado pelos ácaros. Segundo Georghiou \& Taylor (1977a) organismos que apresentam várias 
gerações por ano, desenvolvem resistência com mais freqüência e de forma mais rápida que organismos que apresentam poucas gerações por ano.

A influência do hábito alimentar sobre a dinâmica da resistência de $T$. urticae e P. ulmi ao acaricida dicofol foi estudada por Dennehy et al. (1990) em pomares de maçã no Estado de Nova York - EUA. Nesse estudo foi observado que a resistência de $T$. urticae era instável enquanto a de $P$. ulmi se mostrava estável. T. urticae por apresentar hábito alimentar polífago, encontra-se em grande número de espécies hospedeiras, assim ácaros suscetíveis presentes em áreas não tratadas (áreas de refúgio) teriam a possibilidade de migrar para as áreas tratadas, diluindo a frequiência de resistência. Por sua vez, P. ulmi, uma espécie monófaga, não apresenta áreas de refúgio para os indivíduos suscetíveis, dessa forma não haveria a possibilidade de migração de indivíduos suscetíveis.

O efeito da migração sobre a evolução da resistência de T. urticae aos acaricidas organoestânicos foi simulado por Flexner et al. (1989). Em condições de casa-de-vegetação foram estabelecidas, a partir de populações suscetível e resistente, populações com 90,99 e $99,9 \%$ de ácaros resistentes e uma população controle (resistente). As avaliações foram feitas após três e seis gerações, estimando-se a $\mathrm{CL}_{50}$ de cada população. Após três gerações houve uma moderada reversão da resistência para as populações de 90 e $99 \%$ de resistência. Após seis gerações, até mesmo, a população resistente havia revertido à suscetibilidade. Segundo os autores, essas informações indicam que a migração e o custo adaptativo podem afetar a evolução da resistência em populações de $T$. urticae resistentes aos acaricidas organoestânicos.

$\mathrm{O}$ ácaro da leprose apresenta hábito alimentar polífago sendo encontrado, inclusive, em plantas daninhas que infestam a cultura dos citros (Trindade \& Chiavegato, 1994). Dessa forma, os ácaros suscetíveis presentes nessas plantas daninhas poderiam servir como fontes de reinfestação para as plantas cítricas, o que poderia resultar em uma diminuição na frequiência de 
resistência (Omoto, 1995a). Porém, Omoto (1998) ressalva a necessidade de maiores estudos da influência da reprodução telítoca e sexual de $B$. phoenicis sobre a dinâmica da resistência na presença de migração de indivíduos suscetíveis. Outro ponto importante a ser investigado é, também, a capacidade de dispersão desse ácaro, uma vez que são escassos os trabalhos nessa área.

Os fatores operacionais são divididos em dois grupos: um referente às características do produto químico (persistência, formulação, seletividade a inimigos naturais e grupo químico) e outro às características de aplicação do produto (nível de controle, estágio de desenvolvimento da praga, modo de aplicação e estratégias de uso dos produtos) (Georghiou \& Taylor, 1977b). Com relação à dose e persistência do pesticida, os mesmos autores relatam que imediatamente após a aplicação em campo, a concentração inicial do resíduo pode ser suficientemente alta a ponto de controlar os indivíduos suscetíveis e os resistentes. Após a aplicação, a concentração do resíduo vai decrescendo devido à degradação do produto. Se a degradação ocorrer de forma rápida, tanto os indivíduos suscetíveis como os resistentes estarão expostos à mesma concentração (que controla ambos os indivíduos). Porém, se o produto for persistente, a degradação ocorrerá de forma mais lenta e em algum momento no tempo, ocorrerá uma concentração do resíduo que será suficiente para controlar os indivíduos suscetíveis, mas não o bastante para controlar os indivíduos resistentes. Um produto persistente pode controlar os indivíduos suscetíveis provenientes das áreas de refúgio interferindo, dessa forma, na dinâmica da resistência e favorecendo o desenvolvimento da resistência. Taylor \& Georghiou (1982), por meio de simulações, estudaram a influência da persistência de pesticidas no desenvolvimento da resistência. Nesse estudo, observaram que produtos com meia-vida de 10 dias proporcionaram desenvolvimento da resistência mais rápido do que os produtos com meia-vida de 1 dia. 
Omoto et al. (1995) avaliaram efeito do decréscimo da atividade biológica de resíduos de diferentes idades de dicofol sobre populações suscetível e resistente de $P$. oleivora ao dicofol. Em condições de laboratório a concentração utilizada foi de $500 \mathrm{mg}$ de dicofol/L de água e os bioensaios, com ambas populações, foram realizados diariamente, estendendo-se até ao resíduo de 10 dias de idade. Foi observado que os resíduos de 0 a 2 dias proporcionaram mortalidade de $100 \%$ em ambas populações. Porém, em resíduos com idade a partir de 2 dias, foi detectada uma maior mortalidade na população suscetível. Um experimento semelhante foi também realizado em condições de campo. As avaliações foram feitas aos $0,1,2,4$ e 6 dias após a pulverização, coletando-se os frutos (nas idades de resíduos pré-determinados) no campo e infestando com as populações suscetível e resistente no laboratório. Nesse caso, também, foi observado que as duas populações responderam de forma distinta às diferentes idades de resíduo de dicofol, sendo que a população suscetível sempre apresentou uma maior porcentagem de mortalidade. Porém, resíduos a partir de 6 dias de idade se mostraram pouco tóxicos para ambas populações.

Dessa forma, a compreensão dos fatores envolvidos no desenvolvimento da resistência é de fundamental importância para a implementação de programas de manejo da resistência que visam prevenir, retardar ou reverter a evolução da resistência de pragas a pesticidas (Georghiou \& Taylor, 1986)

\subsubsection{Detecção e monitoramento da resistência}

A deteç̧ão e o monitoramento da resistência de pragas a pesticidas têm sido realizados através da utilização de técnicas de bioensaio. Por meio desses métodos, os organismos testes são expostos a um gradiente de doses ou concentrações de um pesticida e informações como mortalidade e crescimento são avaliadas (ffrench-Constant \& Roush, 1990). Normalmente, o 
monitoramento da resistência tem sido feito por meio da utilização de concentrações diagnósticas ou discriminatórias. Segundo Roush \& Miller (1986), o uso da estimativa da $\mathrm{CL}_{50}$ em programas de monitoramento da resistência é inadequado, uma vez que é pouco preciso em detectar problemas na fase inicial da evolução da resistência (baixa frequiência de resistência). Nesses casos, o monitoramento por meio de concentração diagnóstica é mais eficiente, pois todos os indivíduos amostrados serão submetidos a uma única concentração, aumentando a precisão na deteç̧ão da resistência. Os métodos de bioensaio para a detecção e monitoramento devem ser simples, rápidos, precisos, de baixo custo e simular modo de exposição do pesticida em condições de campo (National Research Council, 1986; ffrench-Constant \& Roush, 1990). ffrench-Constant \& Roush (1990) classificaram os bioensaios em função de como o pesticida é aplicado:

a) bioensaio de imersão: nesse tipo de bioensaio, os organismos são mergulhados em solução de concentração conhecida ou então são oferecidos dietas que contenham o pesticida aos organismos;

b) bioensaio de contato residual: os organismos são expostos a resíduos secos de um pesticida sobre um substrato natural (geralmente folhas) ou artificial (vidro ou plástico);

c) bioensaio de aplicação tópica: nesse bioensaio, doses de um pesticida são aplicados diretamente sobre os organismos, geralmente com auxílio de microseringas.

Segundo ffrench-Constant \& Roush (1990), um método de bioensaio adequado é aquele que maximiza as diferenças entre os indivíduos suscetíveis e resistentes. É também desejado que o bioensaio aumente a magnitude (razão de resistência) entre os genótipos suscetiveis e resistentes e/ou aumente o coeficiente angular da curva de concentração-resposta. Nesse contexto, Dennehy et al. (1983) avaliando a resposta de T. urticae ao dicofol por meio de bioensaios de 
imersão e residual, encontraram uma razão de resistência de apenas seis vezes ao dicofol em bioensaio de imersão; porém, com o bioensaio residual a razão de resistência foi superior a 500 vezes.

Omoto et al. (1995) avaliaram a resposta das populações suscetível e resistente de $P$. oleivora ao dicofol utilizando bioensaio de contato direto e residual (em resíduo contínuo e descontínuo). Observou-se que a resposta foi dependente das populações avaliadas e do modo de exposição ao dicofol. Os bioensaios de contato direto e residual descontínuo proporcionaram uma menor diferenciação entre as populações. O bioensaio residual (resíduo contínuo) proporcionou uma melhor diferenciação. Dessa forma os autores concluíram que o bioensaio residual (resíduo contínuo) seria o melhor método para o monitoramento da resistência.

Um dos grandes problemas envolvendo os trabalhos de detecção e monitoramento da resistência onde se avalia por meio de um bioensaio, a morte ou sobrevivência de um organismo, é a adoção de um critério de mortalidade adequado. A dificuldade em distinguir indivíduos vivos de mortos em bioensaios ocorre com certa frequiência (Hoskins \& Craig, 1962). Segundo Busvine (citado por Welty et al., 1988) em bioensaio residual, os ácaros incapazes de se locomover, mas capazes de algum movimento de perna poderiam ser considerados como mortos. A inclusão de ácaros moribundos como mortos, na avaliação de um bioensaio residual, é correto se os ácaros cessarem a alimentação e a oviposição e tão logo morrerem (Welty et al., 1988). Em trabalho conduzido por Welty et al. (1988), comparando métodos de bioensaio residual e critérios de mortalidade para população de $P$. ulmi resistente ao cihexatin, mostrou que as $\mathrm{CL}_{50}$ das populações suscetível e resistente foram fortemente influenciadas pelo critério de mortalidade adotado. Quando os ácaros moribundos foram considerados vivos, as $\mathrm{CL}_{50}$ estimadas foram 11 e $>316 \mathrm{mg} / \mathrm{L}$ de cihexatin para população suscetivel e resistente, respectivamente e uma concentração de 100 
$\mathrm{mg} / \mathrm{L}$ foi selecionada como sendo a discriminatória. Em contraste, quando os ácaros moribundos foram considerados como mortos, as $\mathrm{CL}_{50}$ estimada para as populações suscetível e resistente foram 1 e $5 \mathrm{mg} / \mathrm{L}$, respectivamente, sendo escolhida uma concentração discriminatória de $3 \mathrm{mg} / \mathrm{L}$

\subsubsection{Resistência de ácaros a acaricidas organoestânicos}

Os acaricidas cihexatin e óxido de fenbutatin, do grupo químico dos organoestânicos, foram identificados no início dos anos 70 e desde então têm sido largamente utilizados em programas de controle de ácaros, principalmente em fruteiras, em função de sua eficiência e seletividade (Croft et al., 1984). No Brasil, os acaricidas organoestânicos são recomendados, principalmente, para o controle de ácaros na cultura de citros. Segundo Jacobson et al. (1999), o acaricida óxido de fenbutatin é um acaricida que age por ingestão e contato, atuando sobre todos os estágios móveis de T. urticae. Após o contato com o produto, os ácaros adultos cessam a alimentação e a postura, chegando a morrer em seguida. $O$ acaricida não apresenta ação ovicida, mas as larvas que eclodem após a pulverização são controladas pelo resíduo do acaricida que se encontra sobre as folhas.

Os acaricidas organoestânicos atuam na respiração celular, inibindo a fosforilação oxidativa (Corbett et al., 1986; Ware, 1989). Trabalho conduzido por Pieper \& Casida (1956) mostrou que a ATPase preparada a partir de tecidos de Musca domestica L., foi inibida por concentrações micromolares de um composto organoestânico (cloreto de trifenitin). Em relação a ácaros, Desaiah et al. (1973) mostraram que a ATPase mitocondrial, proveniente de homogeneizados de $T$. urticae foi inibida pelo acaricida cihexatin.

Carbonaro et al. (1986), estudando os mecanismos de resistência de $T$. urticae ao cihexatin, verificaram que não haviam diferenças na penetração ou no 
metabolismo entre as populações suscetível e resistente ao cihexatin. Porém, foi verificada uma diferença quanto à inibição da atividade da ATPase. A população suscetível apresentou uma $\mathrm{I}_{50}(50 \%$ de inibição da ATPase) de $2,3 \eta \mathrm{M}$ e a população resistente, $15 \eta \mathrm{M}$. Essa diferença na inibição da atividade da ATPase pode ser responsável, em parte, pela resistência ao cihexatin em populações de $T$. urticae.

Vários estudos têm relacionado falhas no controle de $T$. urticae e $P$. ulmi com a utilização de acaricidas organoestânicos ao problema da resistência. $\mathrm{Na}$ Austrália, os casos de resistência têm sido relacionados principalmente em $T$. urticae aos acaricidas cihexatin e óxido de fenbutatin (Edge \& James, 1986; Herron et al., 1994; Goodwin et al., 1995). Edge \& James (1986) detectaram a resistência de $T$. urticae ao cihexatin nas principais regiões produtoras de pêra e maçã da Austrália. A razão de resistência de T. urticae ao cihexatin, observada pelos autores, não foi superior a 15 vezes. Mesmo através pressão de seleção com cihexatin sobre a população mais resistente, não foi possivel aumentar a razão de resistência.

Em trabalho conduzido por Herron et al. (1994), populações de $T$. urticae, oriundas de pomares de pêra, foram avaliadas para a resistência ao óxido de fenbutatin e cihexatin. Uma razão de resistência de 1500 vezes ao óxido de fenbutatin foi verificada em populações de campo, quando comparada à população suscetível. Porém, para cihexatin a razão de resistência foi de apenas 9,8 vezes.

Goodwin et al. (1995) relataram que as falhas de controle de T. urticae em rosas com o acaricida óxido de fenbutatin não poderiam ser relacionadas somente à resistência, e que outros fatores poderiam estar afetando a sua eficiência em condições de campo. 
Nos Estados Unidos, os casos de resistência aos acaricidas organoestânicos têm sido relacionados aos ácaros da família Tetranychidae em fruteiras (Hoyt et al., 1985; Keena \& Granett, 1987; Welty et al., 1987; Hoy et al., 1988; Tian et al., 1992). Hoy et al. (1988) estudando a resistência de Tetranychus pacificus McGregor aos acaricidas cihexatin e óxido de fenbutatin, encontraram que a população resistente apresentava alta razão de resistência para os dois produtos, indicando a presença de resistência cruzada entre cihexatin e óxido de fenbutatin. Hoyt et al. (1985) avaliaram o efeito do tempo de uso de cihexatin no desenvolvimento da resistência em $T$. urticae em pomares de pêras no sudeste de Oregon, onde o uso de organoestânicos foi iniciado a partir de 1972. Nesse trabalho, os autores observaram que em 1978, após 6 anos de exposição às múltiplas aplicações de cihexatin, a razão de resistência de uma população proveniente de um pomar comercial era de apenas 4,1 vezes, indicando uma baixa intensidade de resistência. Porém, em 1980 a população de ácaros provenientes desse mesmo pomar apresentou uma razão de resistência de 24,9 vezes, mostrando que nesses 2 anos houve aumento acentuado na razão de resistência. Tian et al. (1992), testando a susceptibilidade de populações de T. urticae a óxido de fenbutatin e cihexatin, observaram uma diferença na susceptibilidade de 478 e 38 vezes para óxido de fenbutatin e cihexatin, respectivamente.

Com relação a $P$. ulmi, Welty et al. (1987) demonstraram que populações de certos pomares de maçã do oeste de Nova York apresentavam baixa razão de resistência ao cihexatin (12 vezes), quando comparadas a uma população suscetível de campo. Porém, essa intensidade foi o suficiente para causar falhas de controle no campo com o uso de doses recomendadas.

Casos de resistência de ácaros aos acaricidas organoestânicos também têm sido relatados no Canadá, com detecção de populações de $P$. ulmi resistentes ao cihexatin (Pree \& Wagner, 1987) e no Reino Unido, onde Jacobson et al. 
(1999) encontraram uma população de T. urticae, proveniente de rosas, resistente ao óxido de fenbutatin.

\subsection{Manejo da resistência de ácaros a acaricidas}

O manejo da resistência constitui-se num importante componente dos programas de manejo integrado de pragas (MIP); portanto a base do seu manejo está na manipulação de estratégias de uso de produtos químicos e dos componentes bióticos e abióticos do ecossistema agrícola, que podem prevenir ou retardar a evolução da resistência (Metcalf, 1980). Georghiou (1983) dividiu as estratégias de manejo da resistência em três grupos principais: manejo por moderação, manejo por saturação e manejo por ataque múltiplo. O manejo por moderação objetiva reduzir a pressão de seleção. Dentre as principais recomendações dessa estratégia estão a redução na freqüência de aplicação de produtos químicos, controle em reboleiras (quando possível), utilização de produtos seletivos e menos persistentes, aplicação do produto no estágio mais vulnerável da praga e manutenção de áreas não tratadas para servir de refúgio aos indivíduos suscetíveis. $\mathrm{O}$ manejo por saturação tem como objetivo diminuir o valor adaptativo dos indivíduos resistentes na presença de pressão de seleção, através do uso de sinergistas ou altas doses do produto químico. Por fim, manejo por ataque múltiplo envolve a utilização de dois ou mais produtos em rotação ou mistura. Essas táticas exigem que os produtos a serem utilizados apresentem modos de ação diferentes e que não tenham resistência cruzada.

A rotação de produtos fundamenta-se no fato do valor adaptativo dos individuos resistentes a um determinado produto ser menor que o dos indivíduos suscetíveis na presença de um produto alternativo, isto é, a freqüência de resistência a um produto diminui quando outros produtos são utilizados (Georghiou, 1983; Tabashnik, 1989). A mistura de produtos, baseia-se no fato 
dos indivíduos resistentes a um determinado produto serem controlados por um segundo produto e vice-versa. Para o sucesso da mistura, algumas condições devem ser respeitadas, como por exemplo: baixa frequiência de resistência, ausência de resistência cruzada entre os componentes da mistura, o uso da mistura deve ser iniciado antes que a resistência a um dos compostos tenha sido selecionada e que a persistência seja semelhante para os dois produtos (Roush, 1989; Tabashnik, 1989; Denholm \& Rowland, 1992). Porém, a utilização de mistura pode levar a seleção de indivíduos resistentes aos dois componentes da mistura.

Duncombe (1973) relatou um programa de manejo da resistência a nível nacional em Zimbabwe. Nesse país, ácaros do gênero Tetranychus são importantes pragas na cultura do algodão e tornaram-se resistentes aos principais acaricidas organofosforados sistêmicos. Avaliando a suscetibilidade desses ácaros aos diversos acaricidas recomendados para o seu controle, apenas oito acaricidas mostraram-se eficazes. Para preservar a suscetibilidade dos ácaros a esses acaricidas, foi proposto um esquema de rotação de acaricidas, no qual o país seria dividido em três regiões, onde cada uma utilizaria somente dois acaricidas, preferencialmente de grupos químicos distintos, por dois anos consecutivos, trocando os produtos nos dois anos seguintes. De acordo com esse esquema, um mesmo produto seria reutilizado, na mesma área, após seis anos. Segundo Blair (citado por Sawicki, 1989) este esquema de rotação têm apresentado grande sucesso, não indicando a presença de resistência a nenhum dos produtos utilizados na rotação.

Em relação a citros, Omoto et al. (1995) verificaram que a resistência de $P$. oleivora ao dicofol era instável e que a freqüência de resistência diminuía rapidamente na ausência de pressão de seleção. Dessa forma, avaliando o efeito de diferentes regimes de uso do dicofol sobre a freqüência de resistência, definiram que a utilização do dicofol uma vez por ano poderia ser empregada no 
manejo da resistência de $P$. oleivora ao dicofol. O intervalo de um ano foi selecionado uma vez que esse é o menor intervalo de tempo, em que o dicofol pode ser utilizado, o qual favorece o declínio da resistência a níveis existentes antes da última aplicação. Porém, os autores ressalvam que essa recomendação é válida somente para locais onde a resistência está abaixo da freqüência crítica.

No Brasil, Alves (1999) verificou que a resistência de B. phoenicis ao dicofol era instável na ausência de pressão de seleção, ou seja, a população resistente apresentava um menor valor adaptativo em relação à população suscetível. Constatou, também, que os acaricidas óxido de fenbutatin, propargite e fenpiroximate não apresentavam resistência cruzada com o dicofol. Dessa forma, é possível a utilização desses produtos no manejo da resistência de $B$. phoenicis ao dicofol.

Alguns trabalhos têm mostrado que a resistência de ácaros ao acaricidas organoestânicos é instável, isto é, a freqüência de resistência diminui na ausência de pressão de seleção (Edge \& James, 1986; Flexner et al., 1988; Flexner et al., 1989; Hoy, et al., 1988; Pree, 1987; Tian et al., 1992;). Essa característica foi explorada por Flexner et al. (1988) que substituíram, por dois anos, a aplicação de cihexatin por abamectin, em um pomar que apresentava alta freqüência de resistência de T. urticae ao cihexatin. Após o período, retornaram a pulverização com cihexatin e verificaram um melhor desempenho do produto. Segundo os mesmos autores, a utilização de produtos que não apresentam resistência cruzada com os organoestânicos, em rotação ou em mistura, poderiam prolongar a vida útil dos novos acaricidas bem como dos organoestânicos.

Em citros, o manejo integrado de pragas é uma prática consolidada, existindo estudos relacionados a métodos de amostragem da densidade populacional de ácaros (Gravena et al., 1988; Negri, 1994; Salva, 1994; Pinto et al., 1995), a inimigos naturais e seletividade de acaricidas (Komatsu \& Nakano, 1988; Sato et al., 1994; Moraes et al., 1994; Moraes \& Sá, 1995; Yamamoto et 
al., 1995; Reis, 1996). Assim, para a implementação de um programa de manejo da resistência de pragas a pesticidas na cultura de citros, há necessidade de interagir as características bioecológicas da praga com as dos produtos químicos, associadas ao modo de aplicação e estratégias de uso destes produtos. 


\section{MATERIAL E MÉTODOS}

O presente projeto de pesquisa foi desenvolvido no "Laboratório de Resistência de Artrópodes a Pesticidas" do Departamento de Entomologia, Fitopatologia e Zoologia Agrícola da Escola Superior de Agricultura "Luiz de Queiroz", Universidade de São Paulo, Piracicaba - SP, no período de março de 1998 a abril de 2000.

\subsection{Criação de Brevipalpus phoenicis em laboratório}

Os ácaros foram criados em frutos de laranja das variedades Pera Rio ou Valência coletadas no pomar do Departamento de Produção Vegetal da ESALQ/USP. Os frutos foram lavados em água corrente, secados e mergulhados em parafina derretida, deixando-se uma área de aproximadamente $10 \mathrm{~cm}^{2}$ para a colonização do ácaro. Esta área foi circundada com uma barreira de algodão umedecida ou com cola adesiva (marca Tanglefoot ${ }^{\mathbb{B}}$ ) para confinar os ácaros e evitar a entrada de predadores e outros organismos. Antes da transferência dos ácaros, uma mistura de gesso, areia, farinha de trigo e água foi pincelada em alguns pontos da arena. Esse procedimento teve como objetivo simular os sintomas da verrugose, os quais favorecem o desenvolvimento de $B$. phoenicis (Chiavegato, 1986 e Nakano et al., 1987). Cada fruto recebeu de 50 a 100 ácaros fêmeas, totalizando 24 a 36 frutos por população. Os frutos foram acondicionados em caixas plásticas com dimensões de $41 \times 34 \times 14 \mathrm{~cm}$ e mantidos em sala 
climatizada à temperatura de $25 \pm 1{ }^{\circ} \mathrm{C}$, umidade relativa de $70 \pm 10 \%$ e fotofase de $14 \mathrm{~h}$. A renovação dos frutos foi realizada mensalmente, quando um fruto novo era colocado sobre o fruto velho para que ocorresse a transferência dos ácaros.

\subsection{Metodologia de bioensaio}

As respostas das populações de $B$. phoenicis aos acaricidas organoestânicos óxido de fenbutatin e cihexatin foram avaliadas através de um bioensaio residual.

As diversas concentrações de óxido de fenbutatin (Torque $500 \mathrm{SC}^{\circledR}, 500$ $\mathrm{g}$ de óxido de fenbutatin/L - Cyanamid Química do Brasil Ltda.) e cihexatin (Hokko Cyhexatin $500^{\circledR}$, pó molhável, $500 \mathrm{~g}$ de cihexatin/kg - Hokko do Brasil Ltda) foram preparadas a partir da diluição dos produtos comerciais em água destilada. Discos de folha de laranjeira de $2,5 \mathrm{~cm}$ de diâmetro, obtidos por meio de um vazador, foram pulverizados individualmente na superfície adaxial, com o auxílio da torre de Potter (Burkard Manufacturing, Rickmansworth, Inglaterra), calibrada a uma pressão de $68,95 \mathrm{kPa}$ (10 psi). Um volume de $2 \mathrm{~mL}$ de solução foi utilizada na pulverização de modo a se obter uma deposição média de resíduo úmido de $1,56 \mathrm{mg} / \mathrm{cm}^{2}$. Após a pulverização, os discos de folha foram deixados sobre papel toalha para a secagem da solução. Uma vez secos, os discos foram transferidos para placas de petri de $3,5 \mathrm{~cm}$ de diâmetro (Falcon 1008, Becton Dickinson Labware, Lincoln Park, NJ, Estados Unidos) contendo uma camada de mistura não geleificada de ágar-água a 3,0\% no fundo. Com essa mesma mistura foi feita uma barreira na borda do disco para evitar a fuga dos ácaros (adaptado de Vestergaard et al., 1995). Para cada arena foram transferidos 10 ácaros fềmeas adultos, com o auxílio de um pincel de pelos finos e microscópio estereoscópico. 
Após a transferência, as placas foram tampadas e mantidas em câmaras climatizadas (Câmara de Germinação Fanem, Modelo 347 CDG) à temperatura de $25 \pm 1{ }^{\circ} \mathrm{C}$ e fotofase de $14 \mathrm{~h}$.

A mortalidade foi avaliada $24 \mathrm{~h}$ após a transferência dos ácaros. O critério de mortalidade foi baseado no toque de cada ácaro com o auxílio de um pincel. Os indivíduos que não responderam com movimentos vigorosos de seus apêndices foram considerados mortos.

\subsection{Caracterização toxicológica de populações de Brevipalpus phoenicis a óxido de fenbutatin e cihexatin}

Três populações de $B$. phoenicis foram escolhidas para a caracterização toxicológica a óxido de fenbutatin e cihexatin. Uma população de laboratório, mantida na ausência de pressão de seleção com acaricidas desde 1994, foi tomada como a população susceptível de referência (S). Outra população, denominada de Col-1, oriunda de um pomar comercial do Município de Colômbia-SP onde o uso de acaricidas organoestânicos foi bastante intenso e uma terceira população Pir-1, proveniente de um pomar não comercial do Município de Piracicaba-SP.

Para as caracterizações toxicológicas das populações aos dois produtos, foram utilizadas cinco concentrações distribuídas logaritmicamente entre 18 a $180 \mathrm{mg}$ de óxido de fenbutatin ou cihexatin / $\mathrm{L}$ de água destilada [ppm(I.A.)]. Os bioensaios foram repetidos de 3 a 8 vezes para cada concentração do produto ao longo do tempo.

Os dados de mortalidade obtidos para cada população e produto foram submetidos à análise de Próbite (LeOra Software, 1987) para estimar a $\mathrm{CL}_{50}$. Baseada na resposta de concentração-mortalidade, uma concentração diagnóstica foi escolhida para óxido de fenbutatin e cihexatin seguindo os critérios 
apresentados por Roush \& Miller (1986) e ffrench-Constant \& Roush (1990). O bioensaio de concentração diagnóstica foi utilizada para o monitoramento da suscetibilidade de diferentes populações de $B$. phoenicis que receberam distintos regimes de uso de acaricidas organoestânicos.

\subsection{Efeito da umidade na persistência de resíduos de óxido de fenbutatin}

Para a avaliação do efeito da umidade sobre a atividade biológica de resíduos de diferentes idades de óxido de fenbutatin foram testadas duas populações de $B$. phoenicis: $\mathrm{S}$ (população suscetível de referência) e Col-1 proveniente de um talhão de citros que recebeu uma intensa aplicação de acaricidas organoestânicos nos últimos 5 anos

O experimento foi realizado em condições de umidades relativas do ar de $30 \pm 10,50 \pm 10,70 \pm 10$ e $90 \pm 10 \%$. O ajuste dos diferentes níveis de umidade, dentro dos dessecadores, foi obtido através da utilização de solução de ácido sulfúrico $\left(\mathrm{H}_{2} \mathrm{SO}_{4}\right)$ em água destilada, em diferentes concentrações e volumes (Tabela 1). Os dessecadores foram mantidos em sala climatizada à temperatura de $25 \pm 1^{\circ} \mathrm{C}$ e fotofase de $14 \mathrm{~h}$. A umidade, dentro dos dessecadores, foi constantemente monitorada por meio de um termohigrômetro e sempre que uma alteração na umidade relativa no interior dos dessecadores de $\pm 10 \%$ fosse observada, realizava-se um ajuste com adição de $\mathrm{H}_{2} \mathrm{SO}_{4}$ ou água destilada.

O bioensaio utilizado foi o mesmo descrito no item 3.2 , utilizando a concentração diagnóstica de $180 \mathrm{mg}$ de óxido de fenbutatin/L de água destilada [ppm(I.A.)]. Dentro dos dessecadores, as placas permaneceram sem a tampa com o propósito do resíduo do produto sofrer o efeito da umidade relativa. As placas, contendo os discos pulverizados, foram mantidas nos dessecadores por períodos de 1, 3, 5 e 7 dias após a aplicação do produto. Uma vez atingido o período de tempo determinado, as placas foram retiradas do interior dos dessecadores e 
infestadas com os ácaros. Após a infestação as placas foram tampadas e mantidas em câmara climatizada. A avaliação da mortalidade foi realizada após $24 \mathrm{~h}$.

Pada cada tratamento foram realizadas quatro repetições num delineamento experimental inteiramente casualizado em arranjo fatorial, constando de quatro níveis de umidade relativa, duas populações e quatro idades de resíduo. As médias dos dados de porcentagem de mortalidade obtidos em cada tratamento foram comparadas pelo teste de Tukey. O nível de significância adotado foi de $5 \%$.

Tabela 1. Concentrações e volumes de soluções de $\mathrm{H}_{2} \mathrm{SO}_{4}$ em água destilada para obtenção de diferentes umidades relativas no interior dos dessecadores (adaptado de Buxton \& Mellanby, 1934).

\begin{tabular}{ccc}
$\begin{array}{c}\text { Umidade Relativa } \\
(\%)\end{array}$ & $\begin{array}{c}\text { Concentração da Solução } \\
\text { de } \mathrm{H}_{2} \mathrm{SO}_{4} \text { (Normalidade) }\end{array}$ & $\begin{array}{c}\text { Volume de Solução } \\
(\mathrm{ml})\end{array}$ \\
\hline 30 & 19,03 & 300 \\
50 & 12,23 & 150 \\
70 & 8,89 & 100 \\
90 & 3,21 & 50 \\
\hline
\end{tabular}




\subsection{Monitoramento da suscetibilidade de populações de Brevipalpus phoenicis aos acaricidas óxido de fenbutatin e cihexatin}

No primeiro semestre de 1999 foram coletadas populações de $B$. phoenicis provenientes de diferentes pomares comerciais de citros do Estado de São Paulo, onde o histórico de uso de acaricidas tem sido registrado nos últimos anos. Dessa forma, foi possivel identificar em um determinado pomar, talhões que receberam diferentes regimes de uso de acaricidas organoestânicos (Tabela 2). De cada talhão foram coletados 30 a 50 frutos infestados com ácaros, sendo estes estabelecidos em condições de laboratório de acordo com procedimentos de criação descritos no item 3.1. Essas populações foram denominadas de Fischer-1, Fischer-2, ... e Fischer-26 uma vez que foram provenientes de talhões das Fazendas de propriedade da Fischer Agropecuária S.A..

Com base na caracterização toxicológica da população $\mathrm{S}$ ao óxido de fenbutatin e cihexatin, a concentração de $180 \mathrm{mg} / \mathrm{L}$ [ppm(I.A.)] para ambos os produtos foi selecionada como a concentração diagnóstica para o monitoramento da suscetibilidade de populações de $B$. phoenicis a esses acaricidas. No monitoramento com óxido de fenbutatin, as diferentes populações testadas foram submetidas a oito repetições ao longo do tempo e em cada repetição foram utilizados aproximadamente 50 ácaros.

No monitoramento com cihexatin, as populações avaliadas foram submetidas a cinco repetições ao longo do tempo, sendo que em cada repetição foram testados aproximadamente 40 ácaros.

Os dados de porcentagem de sobrevivência $(X)$ das populações para cada monitoramento foram transformados em arc sen $\sqrt{(X / 100)}$. As médias foram comparadas pelo teste bilateral de Dunnett ao nível de $5 \%$ de significância, tendo como referência a média de sobrevivência obtida para a população $S$. 
Tabela 2. Populações de Brevipalpus phoenicis provenientes de pomares comerciais de citros da Fischer Agropecuária S.A. que receberam diferentes regimes de uso de acaricidas organoestânicos no período de 1995-1999.

\begin{tabular}{|c|c|c|c|c|c|}
\hline \multirow[b]{2}{*}{ População } & \multicolumn{5}{|c|}{ Ano de aplicação } \\
\hline & 1995 & 1996 & 1997 & 1998 & 1999 \\
\hline \multicolumn{6}{|l|}{ Fischer-1 } \\
\hline Fischer-2 & $=^{(1)}$ & & & & \\
\hline Fischer-3 & $=$ & $=$ & & & \\
\hline Fischer-4 & & & & & \\
\hline Fischer-5 & & 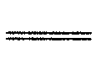 & & $==$ & \\
\hline Fischer- 6 & 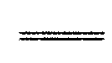 & $=$ & $=$ & & \\
\hline Fischer-7 & $=$ & $=$ & $=$ & & \\
\hline Fischer-8 & $=$ & $=$ & $\overline{ }$ & & $=$ \\
\hline Fischer -9 & $=$ & & $=$ & & $\underline{\overline{ }}$ \\
\hline Fischer-10 & 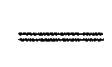 & $=$ & & & $\underline{=}$ \\
\hline Fischer-11 & & $=$ & & & \\
\hline Fischer-12 & & 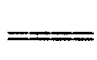 & $\underline{-}$ & & \\
\hline Fischer-13 & & $=$ & $=$ & & \\
\hline Fischer-14 & & $=$ & $=$ & & \\
\hline Fischer-15 & & $=$ & $=$ & & \\
\hline Fischer-16 & & $=$ & 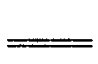 & & $=$ \\
\hline Fischer-17 & & $=$ & $\underline{\underline{ }}$ & & $=$ \\
\hline Fischer-18 & & $=$ & & $==$ & \\
\hline Fischer-19 & & $=$ & & & $=$ \\
\hline Fischer-20 & & & & & \\
\hline Fischer-21 & & & & $=$ & \\
\hline Fischer-22 & & & & 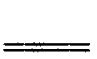 & \\
\hline Fischer-23 & & & & $\underline{\underline{ }}$ & \\
\hline Fischer-24 & & & & $=$ & 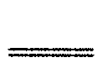 \\
\hline Fischer-25 & & & & & $=$ \\
\hline Fischer-26 & & & & & $\bar{\square}$ \\
\hline
\end{tabular}




\section{RESULTADOS E DISCUSSÃO}

\subsection{Caracterização toxicológica de populações de Brevipalpus phoenicis a óxido de fenbutatin e cihexatin.}

Não foram observadas diferenças significativas em termos de resposta das populações $\mathrm{S}$, Col-1 e Pir-1 tanto para o acaricida óxido de fenbutatin (Tabela 3) como para o cihexatin (Tabela 4).

Para a caracterização toxicológica de $B$. phoenicis ao óxido de fenbutatin foram testados 1760,882 e 816 ácaros para as populações $S$, Col-1 e Pir-1, respectivamente. Para a população $\mathrm{S}$, a $\mathrm{CL}_{50}$ estimada foi de $59,32 \mathrm{mg}$ de óxido de fenbutatin/L de água destilada [I.A.(ppm)] (I.C. 95\% 55,87-63,01) e coeficiente angular ( \pm desvio padrão) de 2,76 $( \pm 0,12), \chi^{2}$ de 2,30 (graus de liberdade (g.1.) $=3 ; P>0,05)$. A CL $\mathrm{AL}_{50}$ estimada para a população Col-1 foi de 85,06 ppm (I.A.) de óxido de fenbutatin (I.C. 95\% 61,42-134,11) e coeficiente angular de $3,21( \pm 0,19), \chi^{2}$ de $8,45($ g.l. $=3 ; P>0,05)$. Já, para a população Bel-1, $\mathrm{CL}_{50}$ estimada foi de 74,33 ppm de óxido de fenbutatin (I.C. $95 \% 60,9-85,96$ ) e coeficiente angular de $3,47( \pm 0,29), \chi^{2}$ de 2,62 (g.1. $\left.=3 ; P>0,05\right)$.

Observando as $\mathrm{CL}_{50} \mathrm{~S}$ estimadas de óxido de fenbutatin para as três populações, verifica-se uma sobreposição dos intervalos de confiança. Essa sobreposição indica que as $\mathrm{CL}_{50} \mathrm{~s}$ estimadas não diferem entre si. Dado semelhante foi obtido por Alves (1999) que realizou a caracterização toxicológica de uma população de $B$. phoenicis ao óxido de fenbutatin, obtendo uma $\mathrm{CL}_{50}$ 
estimada de aproximadamente $67 \mathrm{ppm}$. Portanto, apesar da população Col-1 ter recebido uma intensa pulverização com acaricidas organoestânicos, não foi verificada uma resposta à pressão de seleção.

Tabela 3. Respostas de concentração-mortalidade das populações S, Col-1 e Pir-1 de Brevipalpus phoenicis ao acaricida óxido de fenbutatin.

\begin{tabular}{cccc}
\hline População & $\boldsymbol{n}^{*}$ & $\begin{array}{c}\text { CL50 (mg I.A./L) } \\
\text { (95\% IC) }\end{array}$ & $\begin{array}{c}\text { Coef. Angular } \\
\pm \text { desvio padrão }\end{array}$ \\
\hline S & 1.760 & $\begin{array}{c}59,33 \\
(55,87-63,01)\end{array}$ & $2,76 \pm 0,12$ \\
Col-1 & 882 & 85,06 & $3,21 \pm 0,19$ \\
& & $(61,42-134,11)$ & $3,47 \pm 0,29$ \\
\hline
\end{tabular}

* Número de ácaros testados

Tabela 4. Respostas de concentração-mortalidade das populações S, Col-1 e Pir-1 de Brevipalpus phoenicis ao acaricida cihexatin.

\begin{tabular}{cccc}
\hline População & $\boldsymbol{n}^{*}$ & $\begin{array}{c}\text { CL50 (mg I.A./L) } \\
(\mathbf{9 5 \%} \text { IC) }\end{array}$ & $\begin{array}{c}\text { Coef. Angular } \\
\pm \text { desvio padrão }\end{array}$ \\
\hline S & 977 & $\begin{array}{c}70,52 \\
(56,30-89,85)\end{array}$ & $3,69 \pm 0,20$ \\
Col-1 & 662 & $\begin{array}{c}68,01 \\
(54,21-86,93)\end{array}$ & $3,95 \pm 0,26$ \\
Pir-1 & 675 & 70,31 & $3,99 \pm 0,26$ \\
\hline
\end{tabular}

\footnotetext{
* Número de ácaros testados
} 
Através do teste de paralelismo das linhas de concentração-resposta obtidas para o óxido de fenbutatin através da análise de Próbite (Tabela 3), verifica-se que a população $S$ apresentou um coeficiente angular significativamente menor que as populações Col-1 e Bel-1 $\left(\chi^{2}=6,93\right.$; g.l. $=2$; $P<0,05)$. Segundo alguns autores, o coeficiente angular relaciona-se à homogeneidade de uma população (Hoskins \& Gordon, 1956) ou ao método de bioensaio utilizado para a caraterização toxicológica (ffrench-Constant \& Roush, 1990). Dessa forma, a diferença observada não pode estar relacionada ao método de bioensaio, uma vez que a caracterização toxicológica foi realizada através do mesmo método paras as três populações. Os bioensaios realizados com óxido de fenbutatin apresentaram uma quantidade de ácaros moribundos muito elevado, dificultando a distinção entre indivíduos vivos e mortos. Assim, o menor coeficiente angular, apresentado pela população $S$, pode estar associado ao critério de mortalidade utilizado no início do experimento. Welty et al. (1988) salientam a importância do critério de mortalidade para a avaliação da suscetibilidade de Panonychus ulmi ao acaricida cihexatin e demonstraram que a melhor discriminação entre indivíduos suscetível e resistente ocorreu quando os ácaros moribundos não foram considerados como mortos. No entanto, os ácaros moribundos (ou seja, os ácaros com movimentos dos apêndices de forma desordenada e incapazes de se locomover) foram considerados mortos no presente estudo. Esse critério foi adotado devido às observações, em trabalhos preliminares, de que os ácaros moribundos não conseguem sobreviver $72 \mathrm{~h}$ após a infestação.

Para a caracterização toxicológica de $B$. phoenicis ao acaricida cihexatin foram utilizados 977, 662 e 675 ácaros fêmeas adultos para as populações S, Col1 e Pir-1, respectivamente. Para a população $\mathrm{S}$, a $\mathrm{CL}_{50}$ estimada foi de $70,52 \mathrm{ppm}$ (I.A.) de cihexatin (I.C. $95 \% 56,30-89,85)$ e coeficiente angular de 3,67 $( \pm 0,20)$, 
$\chi^{2}$ de 12,21 (g.1. $\left.=3 ; P>0,05\right) . \quad \mathrm{A} \mathrm{CL}_{50}$ estimada para a população Col-1 foi de 68,01 ppm de cihexatin (I.C. 95\% 54,21-86,93) e coeficiente angular de 3,95 $( \pm 0,26), \chi^{2}$ de $8,95($ g.l. $=3 ; P>0,05)$. Já, para a população Pir-1, a $C_{50}$ estimada foi de 70,31 ppm de cihexatin (I.C. 95\% 60,68-81,98) e coeficiente angular de $3,99( \pm 0,29), \chi^{2}$ de 4,06 (g.1. $\left.=3 ; P>0,05\right)$ (Tabela 4).

Observando as $\mathrm{CL}_{50} \mathrm{~s}$ estimadas das três populações ao cihexatin, verifica-se uma sobreposição dos intervalos de confiança. Essa sobreposição indica que as $\mathrm{CL}_{50}$ S estimadas para as populações $\mathrm{S}$, Col-1 e Pir-1 não diferem entre si, evidenciando que a intensidade de uso de acaricidas organoestânicos não interferiu na mudança da $\mathrm{CL}_{50}$.

Por meio do teste de paralelismo das linhas de regressão estimada pela análise de Próbite, observou-se que a resposta das três populações foram semelhantes ao acaricida cihexatin $\left(\chi^{2}=1,07 ;\right.$ g.l. $\left.=2 ; P>0,05\right)$ (Tabela 4$)$.

Baseado na linha de concentração-resposta da população $S$ ao óxido de fenbutatin (Figura 1) e cihexatin (Figura 2) a concentração de 180 ppm foi definida para os dois produtos como uma concentração diagnóstica a ser utilizada em programas de monitoramento da suscetibilidade de populações de $B$. phoenicis a esses acaricidas. Nessa concentração, a mortalidade da população S é de aproximadamente $95 \%$ a $99 \%$ tanto para óxido de fenbutatin como para cihexatin.

Os testes toxicológicos mostraram que as três populações responderam de forma semelhante aos acaricidas óxido de fenbutatin e cihexatin. Esses resultados podem ser em função dos testes terem sido realizados em condições de laboratório onde, geralmente, há uma maior uniformidade de pulverização e um contato bastante intenso entre a praga e o produto, não havendo possibilidade dos ácaros escaparem para locais não tratados. Portanto, o bioensaio utilizado em laboratório pode não ser suficientemente acurado a ponto de discriminar os 
indivíduos resistentes, subestimando o problema da resistência. Em condições de campo, a pulverização é desuniforme, sendo que o contato entre a praga e o produto ocorre de forma descontínua. Em campo ocorre, também, uma perda na atividade biológica do resíduo do produto com o passar do tempo e em algum momento pode haver uma concentração do resíduo que seja suficiente para controlar os indivíduos suscetíveis, mas não para controlar os resistentes, ocorrendo assim a evolução da resistência. 


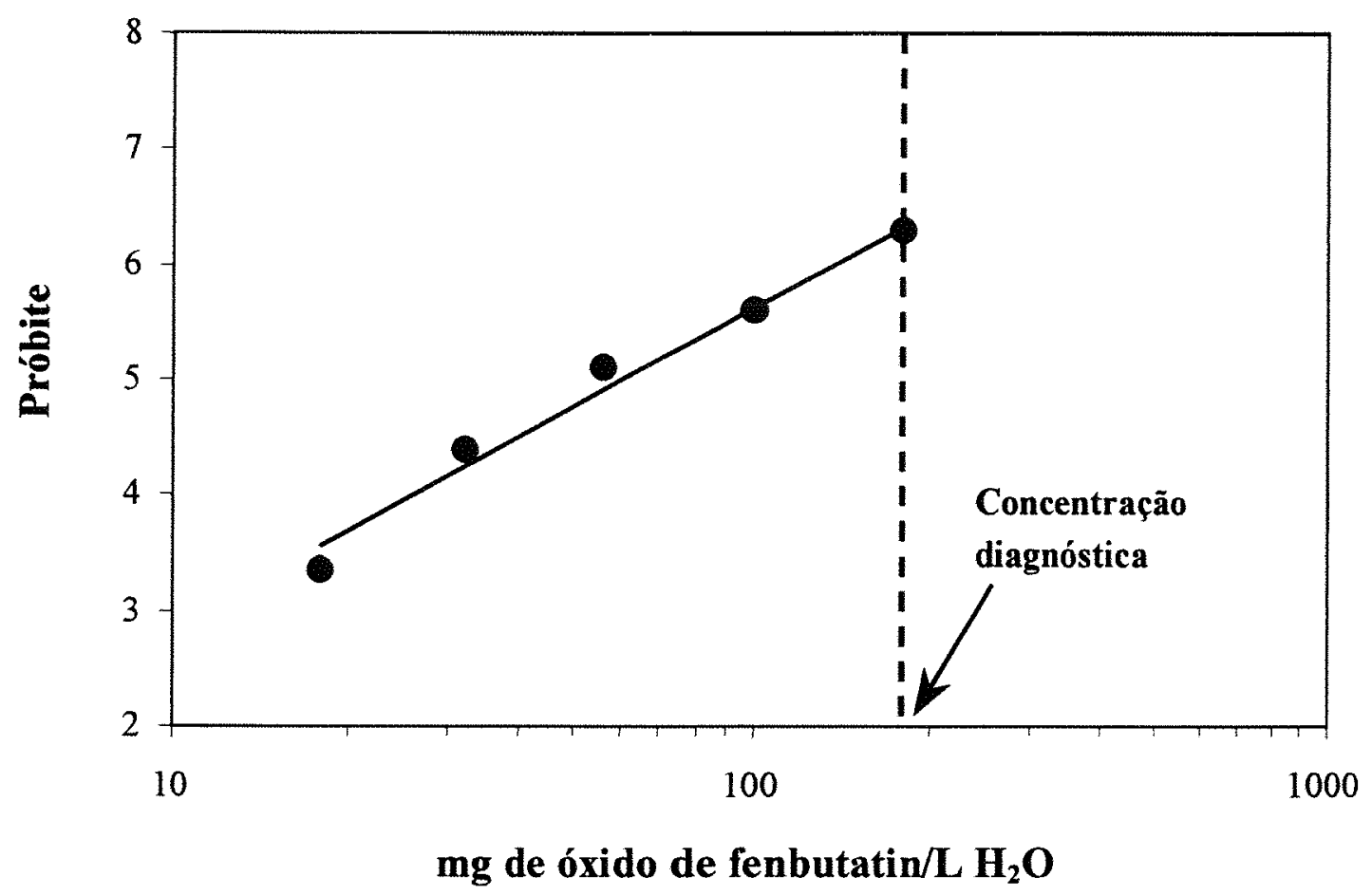

Figura 1. Linha básica de suscetibilidade da população $\mathrm{S}$ de Brevipalpus phoenicis ao acaricida óxido de fenbutatin por meio de um bioensaio residual. A seta indica a concentração diagnóstica de $180 \mathrm{mg} / \mathrm{L}$ (ppm). 


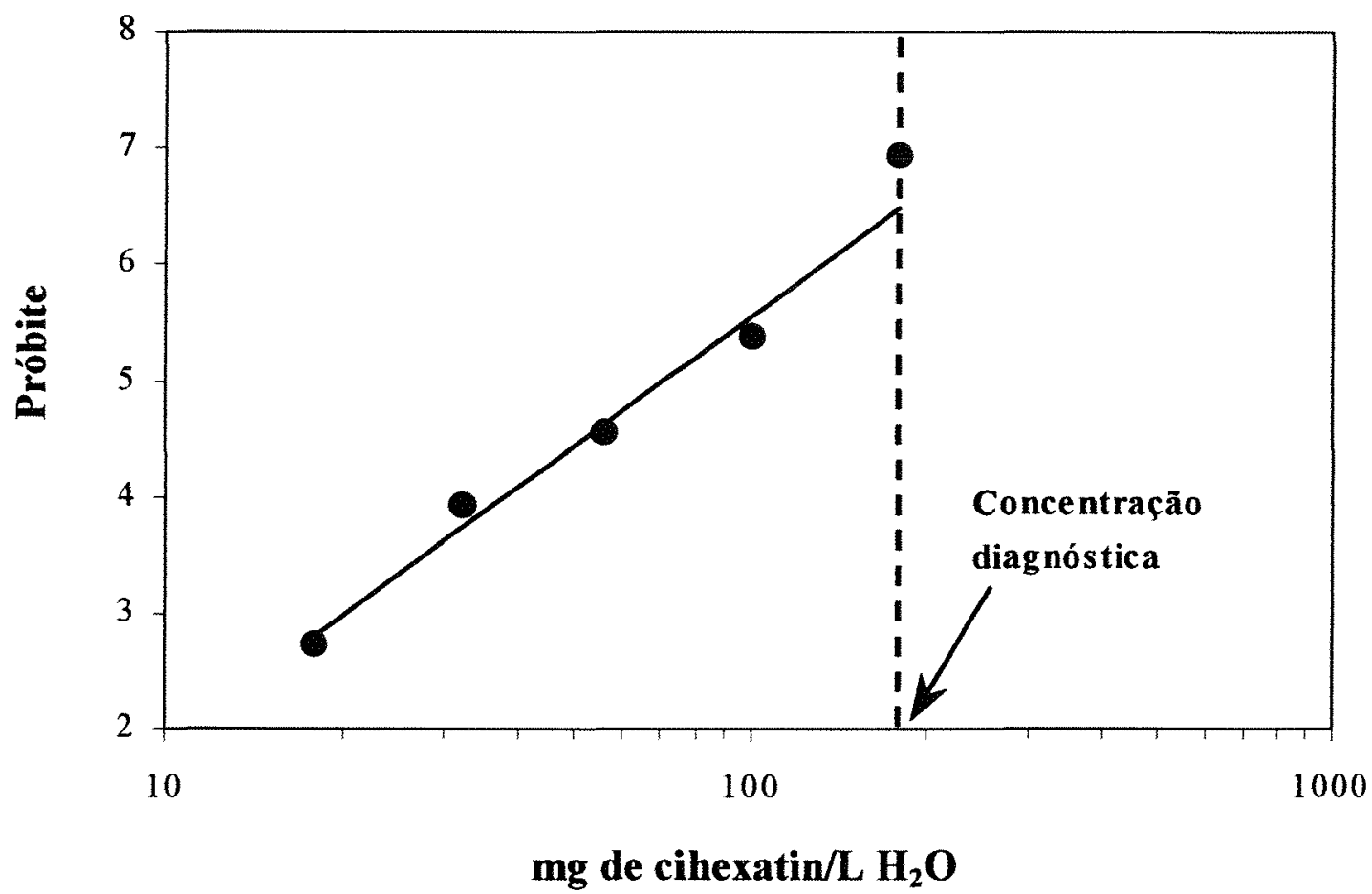

Figura 2. Linha básica de suscetibilidade da população $\mathrm{S}$ de Brevipalpus phoenicis ao acaricida cihexatin por meio de um bioensaio residual. A seta indica a concentração diagnóstica de $180 \mathrm{mg} / \mathrm{L}(\mathrm{ppm})$. 


\subsection{Efeito da umidade na persistência de resíduos de óxido de fenbutatin}

As diferentes umidades relativas testadas não interferiram na degradação da atividade biológica de resíduos de óxido de fenbutatin em condições laboratoriais (Tabela 5). Essa degradação não proporcionou diferenças na suscetibilidade das populações $\mathrm{S}$ e Col-1 ao óxido de fenbutatin.

O efeito da interação da população e umidade não foi significativo $(F=$ $0,33$; g.1. $=3,96 ; P>0,05)$, sendo que as populações $\mathrm{S}$ e Col-1 comportaram-se de forma semelhante, dentro das diferentes idades de resíduos de óxido de fenbutatin expostos, tanto em condições de baixa umidade relativa como em alta umidade. Da mesma forma, o efeito da população não foi significativo ( $F=$ $0,94 ;$ g.l. $=1,96 ; P>0,05)$. As duas populações apresentaram a mesma resposta frente aos residuos de diferentes idades (Tabela 5 e Figura 3).

O efeito da umidade relativa (UR) sobre a persistência de resíduos de mesma idade de óxido de fenbutatin não foi significativo $(F=2,53 ;$ g.l. $=9,96$; $P>0,05)$. As populações S e Col-1 responderam de forma semelhante em todas as umidades testadas, dentro de cada idade de resíduo. A população $S$ apresentou mortalidade de $100 \%$ em todas as umidades para os resíduos de um e três dias de idade. Para o resíduo de sete dias de idade, as mortalidades foram de 93,6; 94,9; 92,9 e $92,2 \%$ para as umidades de $30,50,70$ e $90 \%$, respectivamente. Segundo observações apresentadas por Nakano (1995), as condições de baixa umidade relativa do ar poderiam favorecer a inativação do óxido de fenbutatin através da sua transformação em hidróxido. Talvez esse processo possa ocorrer em condições de campo sob o efeito conjunto com outros fatores climáticos, tais como radiação solar e temperatura.

Embora não avaliado na presente pesquisa, alguns estudos têm evidenciado o efeito da temperatura sobre a ação de acaricidas organoestânicos. Segundo Everson \& Tonks (1981), a toxicidade do acaricida cihexatin ao ácaro $T$. 
urticae apresentou uma relação direta com o aumento da temperatura. $\mathrm{O}$ efeito da temperatura na toxicidade do acaricida cihexatin sobre populações de $T$. urticae suscetivel e resistente ao cihexatin foi avaliado por James et al. (1988) e, em condições de laboratório, a toxicidade do cihexatin mostrou uma relação direta com o aumento da temperatura. Foi observado que quando os testes foram conduzidos à temperatura de $20^{\circ} \mathrm{C}, \mathrm{a} \mathrm{CL}_{50}$ da população resistente foi 13,1 vezes superior ao da população suscetível. Porém, à $15^{\circ} \mathrm{C}$ a razão de resistência foi de 125,1 vezes. Dessa forma, os autores concluíram que a redução da toxicidade do cihexatin em baixas temperaturas poderia ser devido ao aumento da destoxificação ou à redução da atividade biológica do acaricida. Assim, falhas de controle de $B$. phoenicis com o uso de acaricidas organoestânicos podem estar relacionados à temperatura no momento da aplicação.

$\mathrm{O}$ fator tempo mostrou ser o único significativo sobre a atividade biológica de resíduos de óxido de fenbutatin $(F=89,32 ;$ g.l. $=3,96 ; P<0,05)$. Os dados de porcentagem de mortalidade nas diferente idades do resíduo de óxido de fenbutatin na umidade de encontram-se na Tabela 5 e Figura 3. A perda na atividade biológica do óxido de fenbutatin foi observada a partir de resíduos de 5 dias de idade para a população S. 
Tabela 5. Efeito da umidade relativa do ar na atividade biológica de resíduos de diferentes idades de óxido de fenbutatin, na concentração diagnóstica de $180 \mathrm{mg} / \mathrm{L}$ (ppm) de óxido de fenbutatin, sobre população S e Col-1 de Brevipalpus phoenicis.

\begin{tabular}{cccc}
\hline \multirow{2}{*}{$\begin{array}{c}\text { Idade do Resíduo } \\
\text { (dias) }\end{array}$} & $\begin{array}{c}\text { Umidade Relativa } \\
(\%)\end{array}$ & \multicolumn{2}{c}{ Mortalidade Média (\%) } \\
\cline { 3 - 4 } & 30 & $100,0 \mathrm{Aa}$ & Col-1 \\
\hline \multirow{2}{*}{1} & 50 & $100,0 \mathrm{Aa}$ & $100,0 \mathrm{Aa}$ \\
& 70 & $100,0 \mathrm{Aa}$ & $100,0 \mathrm{Aa}$ \\
& 90 & $100,0 \mathrm{Aa}$ & $100,0 \mathrm{Aa}$ \\
\hline 3 & 30 & $100,0 \mathrm{Aa}$ & $100,0 \mathrm{Aa}$ \\
& 50 & $100,0 \mathrm{Aa}$ & $100,0 \mathrm{Aa}$ \\
& 70 & $100,0 \mathrm{Aa}$ & $99,4 \mathrm{Aa}$ \\
& 90 & $100,0 \mathrm{Aa}$ & $100,0 \mathrm{Aa}$ \\
\hline 5 & 30 & $98,1 \mathrm{Ba}$ & $97,1 \mathrm{ABa}$ \\
& 50 & $95,6 \mathrm{Ba}$ & $97,0 \mathrm{ABa}$ \\
& 70 & $97,5 \mathrm{Ba}$ & $96,1 \mathrm{ABa}$ \\
& 90 & $98,1 \mathrm{ABa}$ & $97,4 \mathrm{ABa}$ \\
\hline & 30 & $93,6 \mathrm{Ca}$ & $96,1 \mathrm{ABa}$ \\
& 50 & $94,9 \mathrm{BCa}$ & $95,6 \mathrm{ABa}$ \\
& 70 & $92,9 \mathrm{Ca}$ & $94,4 \mathrm{Ba}$ \\
& 90 & $92,2 \mathrm{Ca}$ & $93,6 \mathrm{Ba}$ \\
\hline & & &
\end{tabular}

Médias seguidas por mesma letra, maiúsculas na coluna e minúscula na linha, não diferem entre si, pelo teste de Tukey, ao nível de $5 \%$ de probabilidade. 

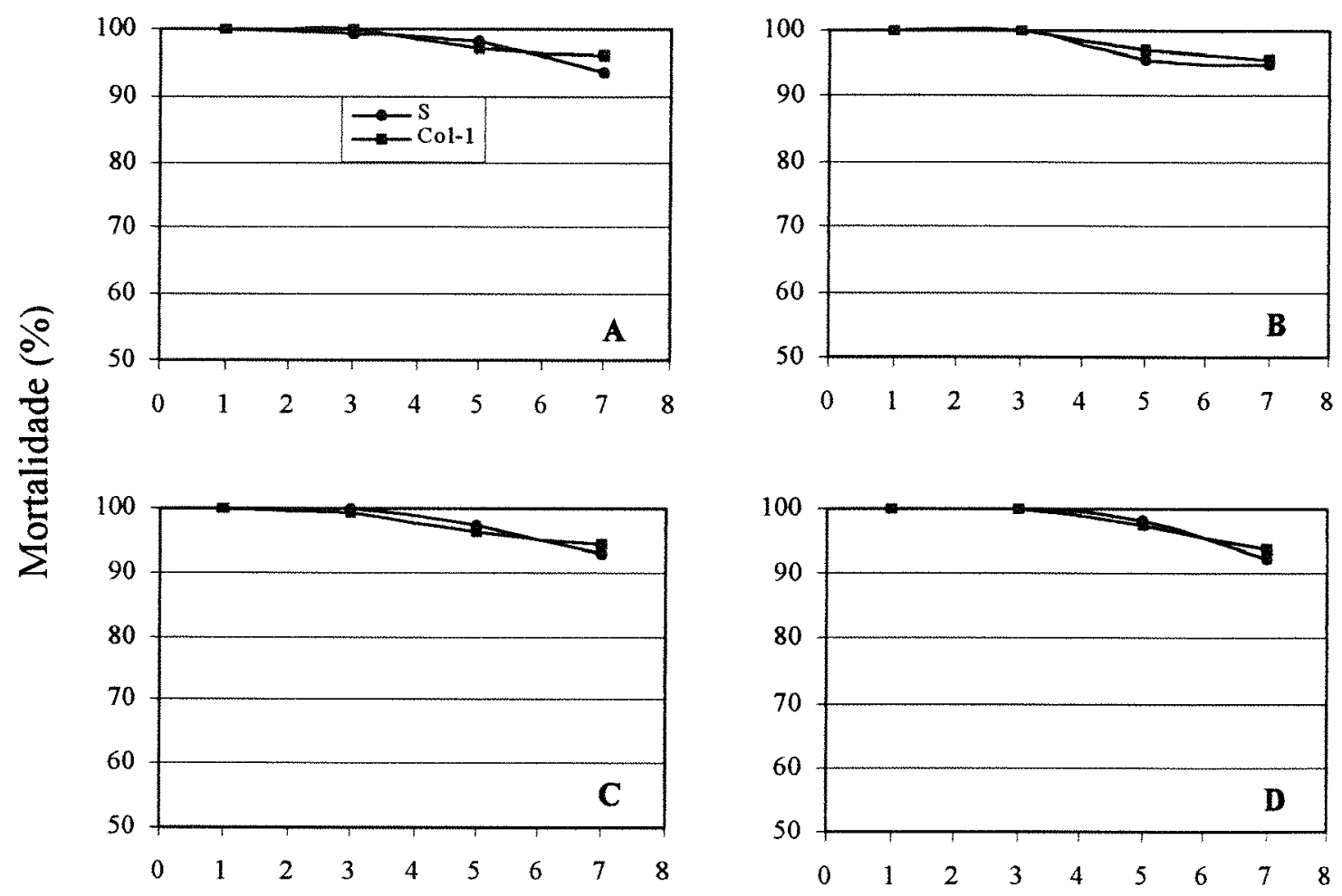

Idade do resíduo de óxido de fenbutatin (dias)

Figura 3. Porcentagem de mortalidade das populações S e Col-1 de Brevipalpus phoenicis em função das diferentes idades do resíduo de óxido de fenbutatin submetidos às umidades relativas de $30 \%(\mathrm{~A}), 50 \%(\mathrm{~B})$, $70 \%$ (C) e $90 \%$ (D). 


\subsection{Monitoramento da suscetibilidade de populações de Brevipalpus phoenicis aos acaricidas óxido de fenbutatin e cihexatin}

Óxido de Fenbutatin: Todas as populações avaliadas mostraram-se altamente suscetíveis, não diferindo estatisticamente da população $\mathrm{S}$ (testemunha) $(F=1,04 ;$ g.l. $=19,140 ; P>0,05)$. As médias de porcentagens de sobrevivência das diversas populações de $B$. phoenicis à concentração diagnóstica de $180 \mathrm{mg} / \mathrm{L}$ (ppm) de óxido de fenbutatin se encontram na Tabela 6 e Figura 4. A sobrevivência variou de $0,12 \%$ a $2,33 \%$, sendo que a população $S$ apresentou uma sobrevivência de $0,28 \%$. A população Fischer-8, que recebeu quatro pulverizações com acaricidas organoestânicos no período de 1995-1999 apresentou uma sobrevivência de apenas $0,75 \%$. A população Fischer-1, que não sofreu pressão seletiva com acaricidas organoestânicos no período de 1995-1999, apresentou sobrevivência de $0,37 \%$.

Cihexatin: Em geral, as diversas populações de B. phoenicis mostraram-se, também, bastante suscetíveis ao cihexatin. As médias de porcentagens de sobrevivência das diversas populações de $B$. phoenicis à concentração diagnóstica de $180 \mathrm{ppm}$ de cihexatin se encontra na Tabela 7 e Figura 5. Apenas a resposta da população Col-1 foi significativamente diferente da população $\mathrm{S}(F=2,63 ;$ g.l. $=19,80 ; P<0,05)$, que apresentou uma sobrevivência média de $10,72 \%$ na concentração diagnóstica. A população $S$ apresentou uma sobrevivência média de 1,92\%. A população Fischer-1 não foi monitorada uma vez que foi perdida devido a problemas na criação. Neste caso, a população Fischer-2 recebeu a menor intensidade de uso de acaricidas organoestânicos (apenas uma pulverização em 1995 no período de 1995-1999) apresentou uma sobrevivência de 4,05\%. A população Fischer-8 (4 pulverizações 
de organoestânicos no período de 1995-1999) apresentou uma sobrevivência de apenas $6,01 \%$.

No presente estudo foi caracterizado a concentração diagnóstica de 180 ppm de óxido de fenbutatin e cihexatin, que poderá ser utilizada em programas futuros de monitoramento da suscetibilidade de populações de B. phoenicis a esses acaricidas

Apesar do intenso uso de acaricidas organoestânicos para o controle de B. phoenicis em citros no Estado de São Paulo, as populações desse ácaro ainda apresentam um alta suscetibilidade a óxido de fenbutatin e cihexatin. O efeito da intensidade de uso de acaricidas organoestânicos na evolução da resistência foi estudado por Flexner et al. (1995). Nesse estudo observaram que quando $T$. urticae, em pomar de pêra, era controlado com acaricidas organoestânicos em alternância com acaricidas que não apresentavam resistência cruzada, a evolução da resistência aos acaricidas organoestânicos se dava de forma mais lenta, quando comparados aos tratamentos onde eram utilizados somente acaricidas organoestânicos. Dessa forma, analisando o histórico de aplicações de acaricidas no periodo de 1995 a 1999 nas populações de B. phoenicis avaliadas no presente estudo (Tabela 2; página 28), observamos que nos pomares que receberam o maior número de aplicações de acaricidas organoestânicos, o seu uso foi no máximo de uma aplicação por ano. Talvez, esse regime de uso de acaricidas organoestânicos (uma aplicação a cada 12 meses) tenha possibilitado o restabelecimento anual da suscetibilidade de populações de $B$. phoenicis a esse grupo de acaricida. Nessas condições, a rotação de acaricidas organoestânicos com outros grupos de acaricidas seria altamente desejável (Omoto, 1995b; 1998).

Os acaricidas organoestânicos atuam de modo distinto dos demais pesticidas utilizados em citros; ou seja, na respiração celular através da inibição da fosforilação oxidativa (Corbett et al. 1986; Ware, 1989). Outros grupos de acaricidas que atuam na mitocôndria (por ex.: pirroles, pirazóis, propargite, 
enxofre, etc.) agem em processos bioquímicos diferentes. Sendo assim, a pressão de seleção com acaricidas organoestânicos em $B$. phoenicis tem sido apenas com os produtos utilizados diretamente para o seu controle. Por outro lado, o uso de dicofol no controle de $B$. phoenicis pode ser afetado pelo uso de bromopropilato para o controle de Phyllocoptruta oleivora num mesmo pomar devido à resistência cruzada (Alves, 1999). Acaricidas piretróides ou nor-pirétricos (por ex.: bifentrina, fenpropatrina, acrinatrina, etc. ) podem sofrer a pressão de seleção através do uso de inseticidas piretróides no controle de outras pragas em citros. Portanto, a definição de uma estratégia de uso de produtos químicos em um determinado pomar deve ser realizado através da análise conjunta de todo complexo de pragas que ocorrem em um determinado pomar. 


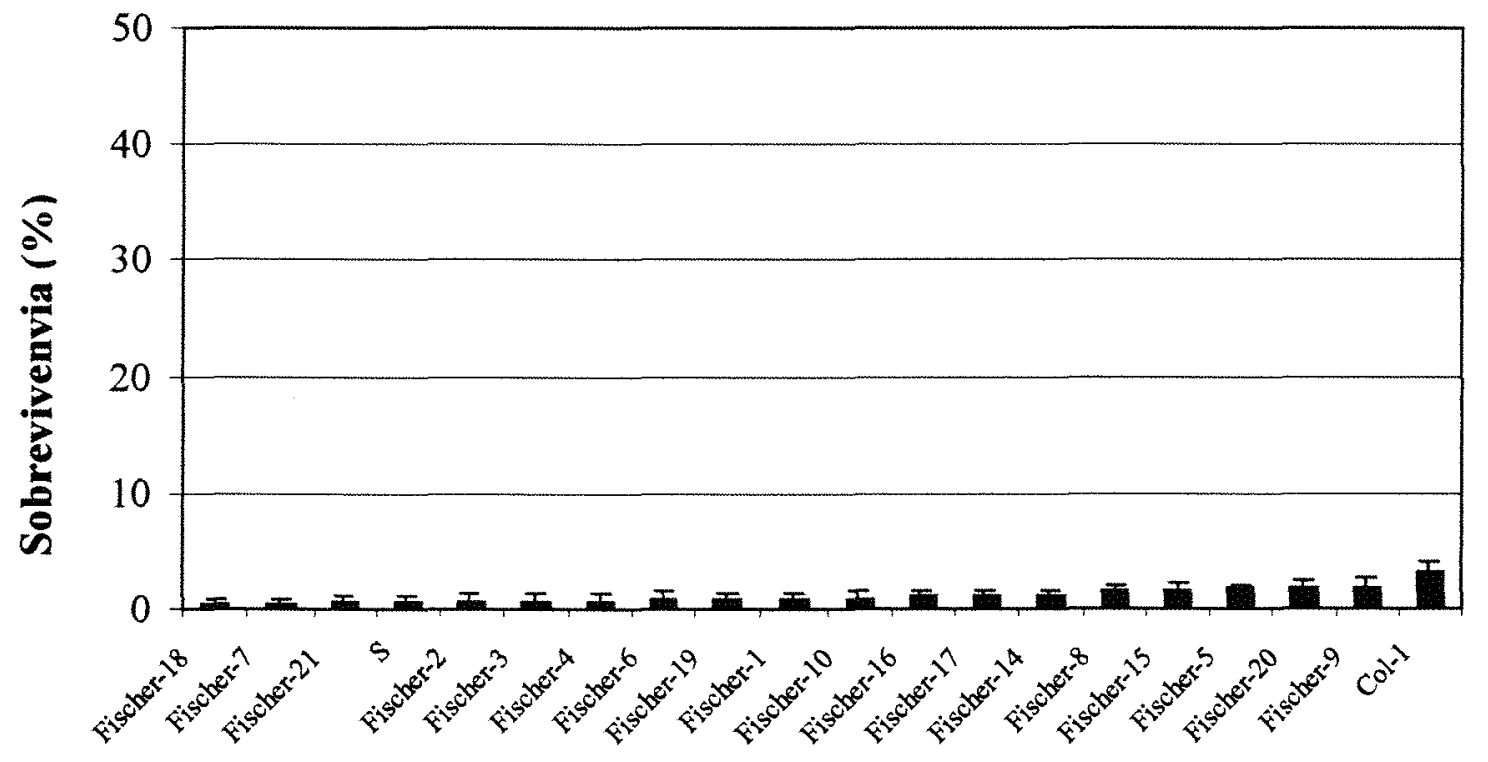

\section{Populações}

Figura 4. Médias de sobrevivência $( \pm E P M)$ em diferentes populações de Brevipalpus phoenicis submetidas à concentração diagnóstica de 180 $\mathrm{mg} / \mathrm{L}$ (ppm) de óxido de fenbutatin. 
Tabela 6. Resposta de diferentes populações de Brevipalpus phoenicis à concentração diagnóstica de $180 \mathrm{mg} / \mathrm{L}$ (ppm) de óxido de fenbutatin.

\begin{tabular}{|c|c|c|}
\hline População & $\begin{array}{c}\text { Número de ácaros } \\
\text { testados } \\
\end{array}$ & Médias de Sobrevivência (\%) \\
\hline S (Testemunha) & 396 & $0,28 \mathrm{a}^{1}$ \\
\hline Col-1 & 386 & $2,33 \mathrm{a}$ \\
\hline Fischer-9 & 409 & $1,26 \mathrm{a}$ \\
\hline Fischer-20 & 399 & $1,07 \mathrm{a}$ \\
\hline Fischer-5 & 406 & $1,01 \mathrm{a}$ \\
\hline Fischer-15 & 397 & $0,92 \mathrm{a}$ \\
\hline Fischer-8 & 407 & $0,75 \mathrm{a}$ \\
\hline Fischer-14 & 398 & $0,50 \mathrm{a}$ \\
\hline Fischer-17 & 398 & $0,49 \mathbf{a}$ \\
\hline Fischer-16 & 412 & $0,43 \mathrm{a}$ \\
\hline Fischer-10 & 395 & $0,38 \mathrm{a}$ \\
\hline Fischer-1 & 388 & $0,38 \mathrm{a}$ \\
\hline Fischer-19 & 395 & $0,37 \mathrm{a}$ \\
\hline Fischer- 6 & 396 & $0,36 \mathrm{a}$ \\
\hline Fischer-4 & 397 & $0,28 \mathrm{a}$ \\
\hline Fischer-3 & 397 & $0,19 \mathrm{a}$ \\
\hline Fischer-2 & 397 & $0,18 \mathrm{a}$ \\
\hline Fischer-21 & 402 & $0,18 \mathrm{a}$ \\
\hline Fischer-7 & 395 & $0,12 \mathrm{a}$ \\
\hline Fischer-18 & 397 & $0,12 \mathrm{a}$ \\
\hline
\end{tabular}

Médias seguidas de mesma letra, na mesma coluna, não diferem da testemunha, pelo teste bilateral de Dunnett, ao nível de 5\% de probabilidade. 


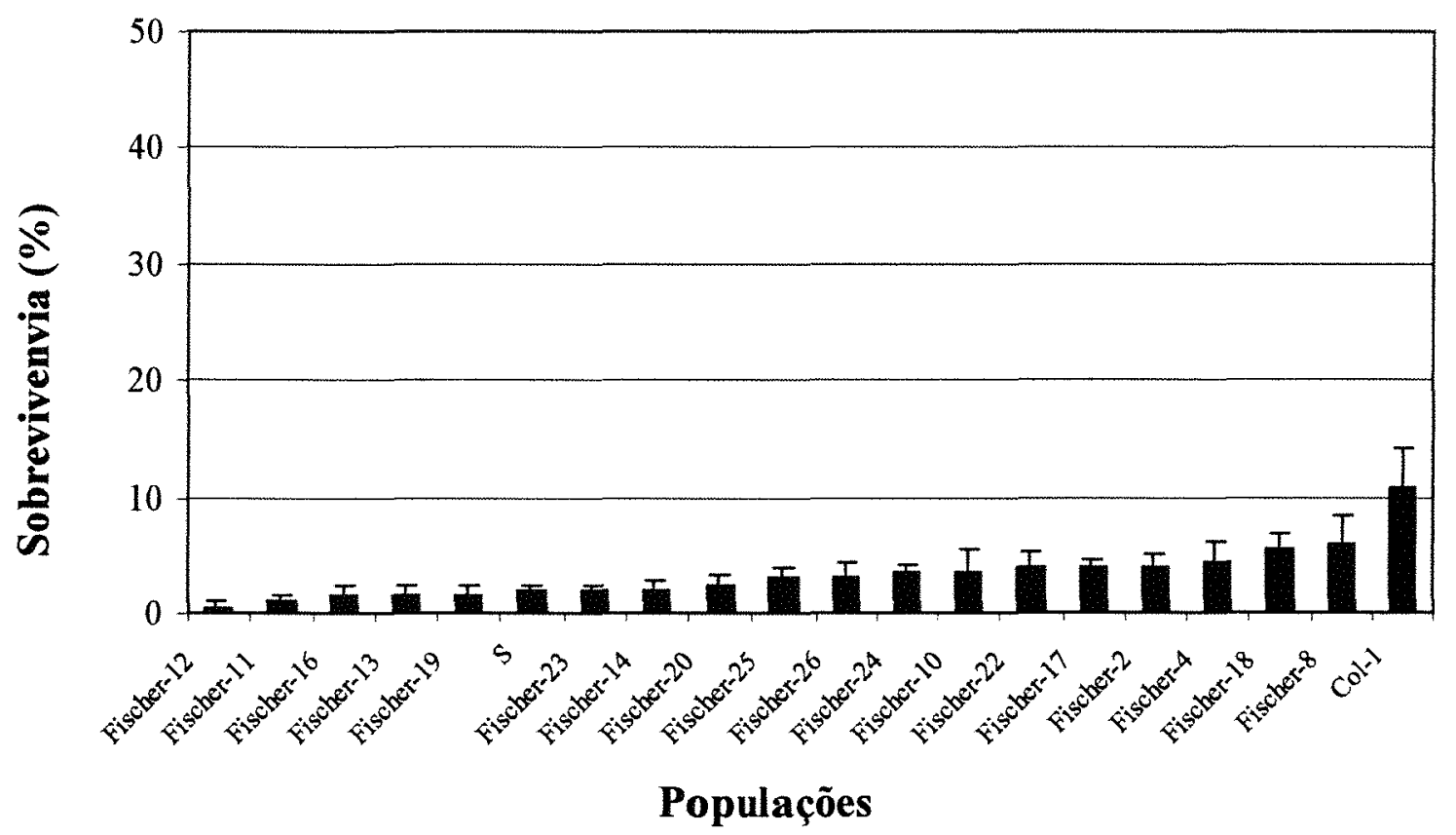

Figura 5. Médias de sobrevivência ( \pm EPM) em diferentes populações de Brevipalpus phoenicis submetidas à concentração diagnóstica de 180 $\mathrm{mg} / \mathrm{L}$ de cihexatin (ppm). 
Tabela 7. Resposta de diferentes populações de Brevipalpus phoenicis à concentração diagnóstica de $180 \mathrm{mg} / \mathrm{L}$ (ppm) de cihexatin.

\begin{tabular}{lcc}
\hline População & $\begin{array}{c}\text { Número de ácaros } \\
\text { testados }\end{array}$ & Médias de Sobrevivência (\%) \\
\hline S (Testemunha) & $\mathbf{2 0 8}$ & $\mathbf{1 , 9 2} \mathrm{a}$ \\
Col-1 & 193 & $10,72 \mathrm{~b}$ \\
Fischer-8 & 199 & $6,01 \mathrm{a}$ \\
Fischer-18 & 201 & $5,48 \mathrm{a}$ \\
Fischer-4 & 200 & $4,50 \mathrm{a}$ \\
Fischer-2 & 198 & $4,05 \mathrm{a}$ \\
Fischer-17 & 199 & $4,01 \mathrm{a}$ \\
Fischer-22 & 200 & $4,00 \mathrm{a}$ \\
Fischer-10 & 198 & $3,53 \mathrm{a}$ \\
Fischer-24 & 199 & $3,49 \mathrm{a}$ \\
Fischer-26 & 194 & $3,09 \mathrm{a}$ \\
Fischer-25 & 201 & $2,98 \mathrm{a}$ \\
Fischer-20 & 205 & $2,44 \mathrm{a}$ \\
Fischer-14 & 199 & $2,00 \mathrm{a}$ \\
Fischer-23 & 201 & $1,99 \mathrm{a}$ \\
Fischer-19 & 201 & $1,50 \mathrm{a}$ \\
Fischer-13 & 198 & $1,50 \mathrm{a}$ \\
Fischer-16 & 202 & $1,48 \mathrm{a}$ \\
Fischer-11 & 205 & $1,00 \mathrm{a}$ \\
Fischer-12 & 200 & $0,50 \mathrm{a}$ \\
\hline Medias &
\end{tabular}

Médias seguidas de mesma letra, na mesma coluna, não diferem da testemunha, pelo teste bilateral de Dunnett (5\%). 


\section{CONCLUSÕES}

- A concentração de $180 \mathrm{mg}$ de [I.A.]/L de água destilada foi definida como uma concentração diagnóstica a ser utilizada em programas de monitoramento da resistência de Brevipalpus phoenicis a óxido de fenbutatin e cihexatin.

- Não houve efeito da idade de resíduos de óxido de fenbutatin, mantidos em diferentes condições de umidade relativa do ar, na discriminação entre indivíduos suscetíveis e resistentes.

- Populações de B. phoenicis coletadas em pomares comerciais de citros com diferentes regimes de uso de acaricidas organoestânicos mostraram-se altamente suscetíveis a óxido de fenbutatin e cihexatin. 


\section{REFERÊNCIAS BIBLIOGRÁFICAS}

ALBUQUERQUE, F.A.; OLIVEIRA, C.A.L.; BARRETO, M. Comportamento do ácaro Brevipalpus phoenicis (Geijskes, 1939) (Acari: Tenuipalpidae) em frutos de citros. In: OLIVEIRA, A.A.L.; DONADIO, L.C. (Ed.). Leprose dos citros. Jaboticabal: FUNEP, 1995. p. 77-90.

ALVES, E.B. Manejo da resistência do ácaro da leprose Brevipalpus phoenicis (Geijskes, 1939) (Aacari: Tenuipalpidae) ao acaricida dicofol. Piracicaba, 1999. 91 p. Dissertação (Mestrado) - Escola Superior de Agricultura "Luiz de Queiroz", Universidade de São Paulo.

BARRETO, M.; PAVAN, A. Relação verrugose X leprose. In: OLIVEIRA, A.A.L.; DONADIO, L.C. (Ed.). Leprose dos citros. Jaboticabal: FUNEP, 1995. p. 69-76.

BUXTON, P.A .; MELLANBY, K. The measurement of control of humidity.

Bull. Ent. Research, v. 25, 1934.

CARBONARO, M.A.; MORELAND, D.E.; EDGE, V.E.; MOTOYAMA, N.; ROCK, G.C.; DAUTERMAN, W.C. Studies on the mechanism of cyhexatin resistance in the twospotted spider mite, Tetranychus urticae (Acari: Tetranychidae). Journal of Economic Entomology, v. 79, n. 3, p.576-579. 
CHIAVEGATO, L.G. Biologia do ácaro Brevipalpus phoenicis em citros. Pesquisa Agropecuária Brasileira, v. 21, n. 8, p. 813-816, 1986.

CHIVEGATO, L.G. A leprose dos citros no Estado de São Paulo. Laranja, v. 8, n. 1,p. 7-19, 1987.

CHIAVEGATO, L.G.; MISCHAN, M.M. Comportamento do ácaro Brevipalpus phoenicis (Geijskes, 1939) (Acari: Tenuipalpidae) em frutos de diferentes variedades cítricas. Científica, v. 15, n. 1/2, p. 17-22, 1987.

CORBETT, J.R.; WRIGHT, K.; BAILLIE, A.C. The biochemical mode of actions of pesticides. London: Academic Press, 1986. cap. 1, p. 1-49: Pesticides interfering with respiration.

CRANHAM, J.E.; HELLE, W. Pesticide resistance in Tetranychidae. In: HELLE, W.; SABELIS, M.W. (Ed.) Spider mites: their biology, natural enemies and control. Amsterdam: Elsevier, 1985. p. 405-421.

CROFT, B.A. Developing a philosophy and program of pesticide resistance management. In: ROUSH, R.T. ; TABASHNIK, B.E. (Ed.) Pesticide resistance in arthropods. New York: Chapman and Hall, 1990. p. 277-296.

CROFT, B.A.; MILLER, R.D.; NELSON, R.D.; WESTIGARD, P.D. Inheritance of early-stage resistance to formetanate and cyhexatin in Tetranychus urticae Koch (Acarina: Tetranychidae). Journal of Economic Entomology, v, 77, n. 3, p. 574-578, 1984. 
CROFT, B.A.; VAN DE BANN, H.E. Ecological and genetic factors influencing evolution of pesticide resistance in tetranychid and phytoseiid mites. Experimental \& Applied Acarology, v. 4, n. 3, p.277-300, 1988.

DENHOLM, I.; ROWLAND, M.W. Tactics for managing pesticide resistance in arthropods: theory and practice. Annual Review of Entomology, v. 37, n. 37, p. 91-112, 1992.

DENNEHY, T.J.; GRANETT, J.; LEIGH, T.F. Relevance of slide-dip and residual bioassay comparisons to detection of resistance in spider mites. Journal of Economic entomology, v.76, n. 6, p.1225-1230, 1983.

DENNEHY, T.J.; NYROP, J.P.; MARTINSSON, T.E. Characterization and exploitation of instability of spider mite resistance to acaricides. In: GREEN, M.B; LeBARON, H.M.; MOBERG, W.K. (Ed). Managing resistance to agrochemicals: from fundamental research to practical strategies. Washington: American Chemical Society, 1990. cap. 5, p. 77-91.

DESAIAH, D.; CUTKOMP, L.K.; KOCH, R.B. Inhibition of spider mite ATPases by Plictran and three organochlorine acaricides. Life Science, v. 13, n. 12, p. 1693-1703, 1973.

DUNCOMBE, W.G. The acaricide spray rotation for cotton. Rhodesia Agricultural Journal, v. 70, n. 5, p. 115-118, 1973.

EDGE, V.E.; JAMES, D.G. Organo-tin resistance in Tetranychus urticae (Acari: Tetranychidae) in Australia. Journal of Economic Entomology, v. 79, n. 6, p. 1477-1483, 1986. 
EVERSON, P.R. \& TONKS, N.V. The effect of temperature on the toxicity of several pesticide to Phitoseiulus persimilis (Acarina: Phytoseiidae) and Tetranychus urticae (Acarina: Tetranychidae). Canadian Entomologist, v. 113 , n. 4 , p. 333-336, 1981.

FFRENCH-CONSTANT, R.H.; ROUSH, R.T. Resistance detection and documentation: the relative roles of pesticide and biochemical assays. In: ROUSH, R.T.; TABASHNIK, B.E. (Ed.). Pesticide resistance in arthropods. New York: Chapman and Hall, 1990. cap. 2, p. 4-48.

FLECHTMANN, C.H.W. Ácaros de importância agrícola. São Paulo: Nobel, 1977. $150 \mathrm{p}$.

FLEXNER, J.L.; THEILING, K.M.; CROFT, B.A.; WESTIGARD, P.H. Fitness and immigration: factors affecting reversion of organotin resistance in the twospotted spider mite (Acari: Tetranychidae). Journal of Economic Entomology, v. 82, n. 4, p.996-1002, 1989.

FLEXNER, J.L.; WESTIGARD, P.H.; CROFT, B.A. Field reversion of organotin resistance in the twospotted spider mite (Acari: Tetranychidae) following relaxation of selection pressure. Journal of Economic Entomology, v.81, n. 6, p. 1516-1520, 1988.

FLEXNER, J.L.; WESTIGARD, P.H.; HILTON, R.; CROFT, B.A. Experimental evaluation of resistance management for twospotted spider mite (Acari: Tetranychidae) on Southern Oregon pear: 1987-1993. Journal of Economic Entomology, v. 88, n. 16, p.1517-1524, 1995. 
GEORGHIOU, G.P. Management of resistance in arthropods. In: GEORGHIOU, G.P.; SAITO, T. (Ed.). Pest resistance to pesticides. New York: Plenum, 1983. p. 769-791.

GEORGHIOU, G.P. The magnitude of the resistance problem. In National Research Council, Pesticide resistance: strategies and tactics for management. Washington: National Academy Press, 1986. p. 14-43.

GEORGHIOU, G.P.; TAYLOR, C.E. Genetic and biological influences in the evolution of insecticide resistance. Journal of Economic Entomology, v. 70, n. 3, p. 319-323, 1977a.

GEORGHIOU, G.P.; TAYLOR, C.E. Operational influences in the evolution of insecticide resistance. Journal of Economic Entomology, v. 70, n. 5, p. 653$658,1977 \mathrm{~b}$.

GEORGHIOU, G.P.; TAYLOR, C.E. Factors influencing the evolution of resistance. In National Research Council, Pesticide resistance: strategies and tactics for management. Washington: National Academy Press, 1986. p. 157-169.

GEORGHIOU, G.P.; TEJEDA, A.L. The occurrence of resistance to pesticides in arthropods. Food and Agriculture Organization of the United Nations. Rome. 1991.318p. 
GOODWIN, S.; HERRON, G.; GOUGH, N.; WELLHAM, T.; ROPHAIL, J.; PARKER, R. Relationship between insecticide-acaricide resistance and field control in Tetranychus urticae (Acari: Tetranychidae) infesting roses. Journal of Economic Entomology, v. 88, n, 5, p. 1106-1112, 1995.

GRAVENA, S. Rotação de acaricidas no MIP-citros: menos desequilíbrio e resistência. Laranja, v. 15, n. 2, p.375-395, 1994.

GRAVENA, S.; FERNANDES, O.A.; PANIZI, W.C. Amostragem seqüencial para os ácaros da falsa ferrugem Phyllocoptruta oleivora (Ashm.) e da leprose Brevipalpus phoenicis (Geijskes) no manejo integrado de pragas dos citros. Laranja, v. 9, p. 147-160, 1988.

HARAMOTO, F.H. Biology and control of Brevipalpus phoenicis (Gejskes, 1939) (Acarina: Tenuipalpidade). Hawaii Agr. Exp. Sta. Tech. Bull, n. 68. 68p. 1969.

HELLE, W.; BOLLAND, H.R.; HEITMANS, W.R. Chromosomes and types of parthenogenesis in the false spider mites (Acari: Tenuipalpidae). Genetica, v. 54, n. 1, p. 45-50, 1980.

HELLE, W.; PIJNACKER, L.P. Parthenogenesis, chromosomes and sex. In: HELLE, W.; SABELIS, M.W. (Ed.). Spider mites: their biology, natural enemies and control. New York: Elsevier, 1985. p. 129-140. 
HERRON, G.A.; EDGE, V.E.;ROPHAIL, J. The influence of fenbutatin oxide use on organotin resistance in two-spotted mite Tetranychus urticae Koch (Acari: Tetranychidae). Experimental \& Applied Acarology, v. 18, n. 11/12, p. $753-755,1994$.

HOSKINS, W.M; GORDON, H.T. Arthropod resistance to chemicals. Annual Review fo Entomology, v. 1, p. 89-122, 1956

HOSKINS, W.M.; CRAIG, R. Uses of bioassay in entomology. Annual Review Entomological, v. 7, p. 437-464, 1962.

HOY, M.A.; CONLEY, J.; ROBINSON, W. Cyhexatin and fenbutatin-oxide resistance in pacific spider mite (Acari: Tetranychidae): stability and mode of inheritance. Journal of Economic Entomology, v. 81, n. 1, p. 57-64, 1988.

HOYT, S.C.; WESTIGARD, P.H.; CROFT, B.A. Cyhexatin resistance in Oregon populations of Tetranychus urticae Koch (Acarina: Tetranychidae). Journal of Ecomonic Entomology, v. 78, n. 3, p. 656-659, 1985.

JACOBSON, R.J.; CROFT, P.; FENLON, J. Response to fenbutatin oxide in populations of Tetranychus urticae Koch (Acari: Tetranychidae) in UK protect crops. Crop Protection, v. 18, n. 1, p. 47-52, 1999.

JAMES, D.G.; EDGE, V.E.; ROPHAIL, J. Influence of temperature on cyhexatin resistance in Tetranychus urticae (Acari: Tetranychidae). Experimental and Applied Acarology, v. 5, n.1, p. 15-21, 1988. 
KEENA, M.A.; GRANETT, J. Cyhexatin and propargite resistance in populations of spider mites (Acari: Tetranychidae) from California almonds. Journal of Ecomonic Entomology, v. 80, n. 3, p. 560-564, 1987

KITAJIMA, E.W.; LOVISOLO, O.; COLARICCIO, A.; CHAGAS, C.M.; ROSSETI, V. Vírus causador da leprose dos citros. In: OLIVEIRA, A.A.L.; DONADIO, L.C. (Ed.). Leprose dos citros. Jaboticabal: FUNEP, 1995. p. 19-24.

KOMATSU, S.S.; NAKANO, O. Estudos visando o manejo do ácaro da leprose em citros através do ácaro predador Euseius concordis (Acari: Phytoseiidae). Laranja, v. 9, p. 125-146, 1988.

LAL, L. Biology of Brevipalpus phoenicis (Geijskes) (Tenuipalpidae: Acarina). Acarologia, v. 20, n. 1, p. 97-101, 1978

LEORA SOFTWARE. POLO-PC: a user's guide to Probit Or LOgit analysis. LeOra software, Berkeley, CA, 1987.

MESSING, R.H.; CROFT, B.A. Pesticide resistance in Eriophyoid mites, their competitors and predators. In: LINDQUIST, E.E.; SABELIS, M.W.; BRUN, J. (Ed.). Eriophyoid mites: their biology, natural enemies and control. New York: Elsevier, 1996. p. 689-694

METCALF, R.L. Changing role of insecticide in crop protection. Annual Review of Entomology, v.25, p. 219-256, 1980. 
MORAES, G.J.; SÁ, L.A.N. Perspectivas do controle biológico do ácaro da leprose em citros. In: OLIVEIRA, C.A.L.; DONADIO, L.C. (Ed.). Leprose dos citros. Jaboticabal: FUNEP, 1995. p. 117-128.

MORAES, G.J.; TAMBASCO, F.J.; SÁ, L.A.N. O controle biológico clássico e o serviço quarentenário no Brasil. In: SEMINÁRIO INTERNACIOANL DE CITROS-MIP, 3., Bebedouro, 1994. Manejo integrado de pragas dos citros: anais. Campinas: Fundação Cargill, 1994. p.77-84.

NAKANO, O. Rotatividade de ingredientes ativos em citros. In: OLIVEIRA, C.A.L.; DONADIO, L.C. (Ed.). Leprose dos citros. Jaboticabal: FUNEP, 1995. p. 189-194.

NAKANO, O.; SANCHES, G.A.; ISHIDA, A.K. Redução na infestação do ácaro da leprose Brevipalpus phoenicis (Geijskes, 1939) em citros através do controle da verrugose. Laranja, v.8, p. 19-33, 1987.

NATIONAL RESEARCH COUNCIL. Prediction or resistance risk assessment. In: National Research Council, Pesticide resistance: strategies and tactics for management. Washington: National Academic Press, 1986. p. 271-278.

NEGRI, J.D. A extensão rural no MIP-citros. In: Seminário Internacional de Citros-MIP, 3., Bebedouro, 1994. Manejo integrado de pragas dos citros: anais. Campinas: Fundação Cargill, 1994, p. 269-275.

OLIVEIRA, C.A.L. Flutuação populacional e medidas de controle do ácaro da leprose Brevipalpus phoenicis (Geijskes, 1939) em citros. Laranja, v. 7. p. 1$31,1986$. 
OLIVEIRA, C.A.L. de. Aspectos ecológicos do Brevipalpus phoenicis. In: OLIVEIRA, C.A.L.; DONADIO, L.C. (Ed.). Leprose dos citros. Jaboticabal: FUNEP, 1995. p. 37-48.

OMOTO, C. Manejo da resistência de ácaros e insetos aos produtos químicos na citricultura. Laranja, v. 16, n. 1, p. 187-208, 1995 a.

OMOTO, C. Resistência de Brevipalpus phoenicis (Acari: Tenuipalpidae) aos produtos químicos na citricultura. In: OLIVEIRA, C. A. L.; DONADIO, L. C. (Ed.). Leprose dos citros. Jaboticabal: FUNEP, 1995b. p. 179-188.

OMOTO, C. Acaricide resistance management of leprosis mite (Brevipalpus phoenicis) in Brazilian citrus. Pesticide Science, v. 52, n, 8, p. 189-198, 1998.

OMOTO, C.; DENNEHY, T.J.; McCOY, C.W.; CRANE, S.E.; LONG, J.W. Management of citrus rust mite (Acari: Eriophyidae) resistance to dicofol in Florida citrus. Journal of Economic Entomology, v. 88, n. 5, p. 1129-1137, 1995.

PIEPER, G.R.; CASIDA, J.E. House fly adenosine triphosphatases and their inhibition by insecticidal organotin compounds. Journal of Economic Entomology, v. 58, n. 5, p. 392-400, 1965.

PINTO, R.A.; YAMAMOTO, P.T.; PAIVA, E.B.; GRAVENA, S. Amostragem seqüencial: uma metodologia rápida e segura. In: OLIVEIRA, C.A.L.; DONADIO, L.C. (Ed.). Leprose dos citros. Jaboticabal: FUNEP, 1995. p. 147-158. 
PREE, D.J. Inheritance and management of cihexatin and dicofol resistance in the European red mite (Acari: Tetranychidae). Journal of Economic Entomology, v. 80, n. 6, p.1106-1112, 1987.

PREE, D.J.; WAGNER, H.W. Occurrence of cyhexatin and dicofol resistance in European red mite, Panonychus ulmi (Koch) (Acari: Tetranychidae) in Southern Ontario. The Canadian Entomologist., v. 119, p.287-290, 1987.

REIS, P.R. Aspectos bioecológicos e seletividade de agroquímicos a Iphiseiodes zuluagai Denmark \& Muma, 1972 (Acari: Phytoseiidae). Piracicaba, 1996. 154p. Tese (Doutorado) - Escola Superior de Agricultura "Luiz de Queiroz", Universidade de São Paulo.

ROSSETTI, V. A leprose dos citros no Brasil. In: OLIVEIRA, A.A.L.; DONADIO, L.C. (Ed.). Leprose dos citros. Jaboticabal: FUNEP, 1995. p. 112.

ROUSH, R.T. Designing resistance management programs? How can you choose? Pesticide Science, v. 26, p.423-441, 1989.

ROUSH, R.T.; McKENZIE, J.A. Ecological genetics of insecticide and acaricide resistance. Annual Review of Entomology, v. 32, n. 2, p. 361-380, 1987.

ROUSH, R.T.; MILLER, GL. Considerations for design of insecticide resistance monitoring programs. Journal of Economic Entomology, v. 79, n. 2, p. 293$298,1986$. 
SALVA, R.A. Prática do monitoramento de MIP-citros no Brasil. In: Seminário Internacional de Citros-MIP, 3., Bebedouro, 1994. Manejo integrado de pragas dos citros: Anais. Campinas: Fundação Cargill, 1994, p. 255-267.

SALVO FILHO, A. Notas sobre o tratamento fitossanitário em citros. Laranja, v. 18, p. $155-163,1997$.

SATO, M.E.; CERÁVOLO, L.C.; CEZÁRIO, A.C.; RAGA, A.; MONTES, S.M.N.M. Toxicidade residual de acaricidas a Euseius citrifolius Denmark \& Muma, 1970 (Acari: Phytoseiidae) em citros. Revista de Agricultura, v. 69, n.3, p. $257-268,1994$

SAWICKI, R.M. Current insecticide management practices in cotton around the world - short-term successes or templates for the future? Pesticide Science, v. 26 , p. $401-410,1989$

TABASHNIK, B.E. Managing resistance with multiple pesticide tactics : theory, evidence, and recommendations. Journal of Economic Entomology, v. 82, n.5, p. 1263-1269, 1989.

TAYLOR, C.E.; GEORGIOU, G.P. Influence of pesticide persistence in evolution of resistance. Environmental Entomology, v.11, n. 3, p. 746-750, 1982.

TIAN, T.; CARDWELL, E.G.; GRANETT, J. Resistance of Tetranychus urticae (Acari: Tetranychidae) to cyhexatin and fenbutatin oxide in California pears. Journal of Economic Entomology, v. 85, v. 6, p. 2088-2095, 1992. 
TRINDADE, M.L.B. Caracterização biológica dos ácaros Brevipalpus obovatus Donnadieu, 1875 Brevipalpus californicus (Banks, 1904) e Brevipalpus phoenicis (Geijskes, 1939) (Acari: Tenuipalpidae) no Estado de São Paulo. Botucatu, 1990, 108p. Dissertação (Mestrado) - Faculdade de Ciências Agronômicas, Universidade Estadual Paulista.

TRINDADE, M.L.B.; CHIAVEGATO, L.G. Caracterização biológica dos ácaros Brevipalpus obovatus D., B. californicus B. e B. phoenicis G. (ACari: Tenuipalpidae). Anais da Sociedade Entomológica do Brasil, v. 23, n. 2, p. 189-195, 1994.

VESTERGAARD, S.; GILLESPIE, A.T.; BUT, T.M.; et al. Pathogenicity of the hyphomycete fungi Verticillum lecanii and Metarhizium anisophiae to the Western flower trips, Frankliniella occidentalis. Biocontrol Science and Technology, v. 5, p. 185-192, 1995.

WARE, G.W. The pesticide book. Fresno: Thompson Publications, 1989. cap. 17, p. 153-166: Modes of action for insecticides.

WELTY, C.; REISSIG, W.H.; DENNEHY, T.J.; WEIRES, R.W. Cyhexatin resistance in New York populations of European red mite (Acari: Tetranychidae). Journal of Economic Entomology, v. 80, n, 1, p. 230-236, 1987.

WELTY, C.; REISSIG, W.H.; DENNEHY, T.J.; WEIRES, R W. Comparison of residual bioassay methods and criteria for assessing mortality of cyhexatinresistant European red mite (Acari: Tetranychidae). Journal of Economic Entomology, v. 81, n. 2, p. 442-448, 1988. 
YAMAMOTO, P.T.; PINTO, A.S.; PAIVA, P.E.B.; GRAVENA, S. Seletividade de acaricidas a inimigos naturais em citros. In: OLIVEIRA, C.A.L.; DONADIO, L.C. (Ed.). Leprose dos citros. Jaboticabal: FUNEP, 1995. p. 159-170. 